\title{
Southern Ocean heat and momentum uptake are sensitive to the vertical resolution at the ocean surface
}

\author{
K.D. Stewarta, ${ }^{\mathrm{a}, \mathrm{b}, *}$, A.McC. Hogg ${ }^{\mathrm{a}, \mathrm{c}}$ \\ ${ }^{a}$ Research School of Earth Sciences, Australian National University, Australia \\ ${ }^{b}$ Climate Change Research Centre, University of New South Wales, Australia \\ ${ }^{c}$ Australian Research Council Centre of Excellence for Climate Extremes
}

\begin{abstract}
The Southern Ocean plays a leading oceanic role in Earth's changing climate, accommodating over two thirds of the excess anthropogenic heat to date. In spite of this, climate and ocean models exhibit substantial variability in Southern Ocean heat uptake and storage, reflecting the modelling challenges of representing the responsible mechanisms. Here, Southern Ocean heat uptake is investigated in a suite of global ocean-sea-ice simulations run over a range of vertical and horizontal resolutions and forced with an idealized thermal perturbation. It is found that the ocean surface speed is sensitive to the vertical resolution at the ocean surface. Subsequently, the wind stress and its curl, which are important factors for Southern Ocean heat uptake, are also sensitive to the vertical resolution at the ocean surface, tending to decrease with refined surface resolution. It follows that the Southern Ocean heat uptake itself is sensitive to the vertical resolution at the surface; indeed, the simulations here with relatively coarse surface resolution $(10 \mathrm{~m})$ exhibit heat content changes at rates nearly double that of simulations with finer surface resolution $(1 \mathrm{~m})$. There is relatively little sensitivity of Southern Ocean heat uptake to the horizontal resolutions examined here $\left(1^{\circ}\right.$ and $\left.0.25^{\circ}\right)$, although the higher resolution simulations exhibit increased wind-driven upwelling. Importantly, all simulations demonstrate that the location of the zero wind stress curl determines the location of the maximum heat uptake. These findings offer guidance for examining Southern Ocean heat uptake and storage in future modelling studies and observations.

Keywords:

Southern Ocean heat uptake; wind stress curl; Ekman/wind-driven upwelling/downwelling, vertical/horizontal resolution
\end{abstract}

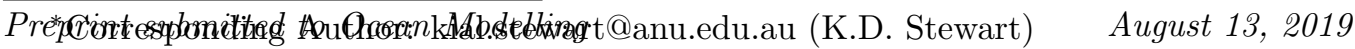




\section{Introduction}

Global warming is predominantly ocean warming, with the oceans storing over $90 \%$ of the excess heat recently trapped in Earth's climate system (Levitus et al. , 2012). Moreover, ocean warming is dominated by Southern Ocean warming, with the Southern Ocean accounting for between 67-98\% of the total ocean warming since 2005 (Roemmich et al., 2015; Llovel \& Terray , 2016). This Southern Ocean warming is strongest in the upper $2 \mathrm{~km}$, primarily a result of the wind-driven advection, ventilation and subduction of Mode and Intermediate Waters and their subsequent circulations, as well as the reduction in high-latitude deep convection. The resulting pattern of warming is complex, time-dependent and inhomogeneous, challenging the limits of observations and representations in global climate models (e.g., Armour et al., 2016; Sallée, 2018). Understanding the governing dynamics of Southern Ocean heat uptake is therefore of leading order importance for understanding and predicting the ocean's response in Earth's changing climate.

Southern Ocean heat uptake in the Coupled Model Intercomparison Project 5th phase (CMIP5) suite of climate models exhibits substantial variability between models; the inter-model standard deviation of total Southern Ocean heat uptake is $40 \%$ of the mean (Frölicher et al. , 2015). The partitioning of heat between the major Southern Ocean water masses in CMIP5 models is also variable, and is biased warm (Sallée et al. , 2013). Furthermore, Southern Ocean heat uptake is particularly sensitive to model biases in their parameterizations of air-sea fluxes and unresolved dynamics (e.g. Huber \& Zanna, 2017). Considering the dominant role of the Southern Ocean in accommodating excess heat from the climate, it is a matter of urgency to improve the representation of Southern Ocean heat uptake in climate models.

Southern Ocean heat uptake is a result of the intricate interplay between surface fluxes of heat and momentum, ocean circulation, and the associated redistribution of the existing oceanic heat reservoir (e.g., Xie \& Vallis, 2011; Frölicher et al. , 2015; Marshall et al., 2015; Armour et al. , 2016). As such, investigations of Southern Ocean heat uptake requires detailed knowledge of all three contributors, all of which have non-trivial dynamics or representations in climate and ocean models (e.g., Morrison et al., 2016). By perturbing the balance of these contributors and examining the ocean response, we can gain insight into their relative influences and potential feedbacks upon 
one another and, ultimately, ocean heat uptake.

Global ocean-sea-ice models, as opposed to fully-coupled climate models, offer a practical means of isolating and attributing oceanic responses to the imposed perturbation in atmospheric forcings. In terms of Southern Ocean heat uptake, global ocean-sea-ice models with imposed, or partiallycoupled, atmospheric thermal conditions are able to reproduce the principle responses of both observations and their fully-coupled climate model counterparts. These responses include a characteristic distribution of the heat uptake and ocean warming: the majority of the additional heat tends to enter the ocean poleward of $\sim 50^{\circ} \mathrm{S}$ and be subsequently advected northward, converging around $45^{\circ} \mathrm{S}$ (e.g. Marshall et al., 2015; Armour et al., 2016; Huber \& Zanna, 2017; Liu et al, 2018). Importantly, the distribution of additional Southern Ocean heat uptake and storage is largely insensitive to the distribution of the atmospheric perturbation, suggesting that the thermal responses are primarily shaped by existing ocean currents rather than circulation changes. Therefore, for modelling the thermal response of the Southern Ocean to changes in atmospheric forcing, it is important to have an accurate representation of the existing ocean circulation, as well as an understanding of its sensitivity to atmospheric forcing and associated perturbations.

One dynamical consequence of the increase in greenhouse gases and stratospheric ozone depletion is the strengthening and poleward shifting of atmospheric winds over the Southern Ocean, which is evident in both observations and global climate models (e.g., Thompson et al. , 2000; Kushner et al. , 2001; Marshall, 2003; Fyfe \& Saenko, 2006; Swart \& Fyfe, 2012). These changes to the wind field influence the momentum uptake by the Southern Ocean, ultimately affecting the heat uptake (e.g., Oke $\&$ England, 2004; Fyfe et al., 2007). Recent work detailed by Llovel \& Terray (2016) uses three gridded Argo products to link the rapid upper ocean warming of the Southern Ocean to enhanced Ekman pumping associated with the poleward shift of the mean wind stress curl field. Their analysis identifies the South-East Indian and South Pacific Oceans as regions with the largest warming signals, where enhanced Ekman pumping acts to deepen isopycnal surfaces and allow for greater penetration of surface heat. That is, the adjustment of the surface momentum fluxes has modified the ocean surface density structure to facilitate additional heat uptake. A corollary to this result is that an adjustment of the surface heat fluxes could also be able to modify the ocean surface density structure (relative to the wind field) such that the ocean is able to uptake additional heat. 
The 6th phase of Coupled Model Intercomparison Project (CMIP6) will feature some ocean models with nominal horizontal resolutions of $0.25^{\circ}$, a refinement from the nominally $1^{\circ}$ models used for CMIP5 (Griffies et al., 2016). It is anticipated that this increased horizontal resolution will improve the representation of mesoscale dynamics and associated variability (e.g., Griffies et al., 2015). These efforts to increase the horizontal resolution can be undermined if unaccompanied by adequate improvements to the vertical resolution (e.g., Stewart et al., 2017). Considering the important role of surface dynamics in Southern Ocean heat uptake, the representation of these surface dynamics in ocean models will likely govern the ability of the model to uptake heat. Thus, vertical resolution at the ocean surface will likely influence the modelled Southern Ocean heat uptake; as it is indeed the case for horizontal resolution (e.g., Spence et al., 2010; Morrison et al., 2013; Newsom et al., 2016). Understanding how resolution (both vertical and horizontal) affects Southern Ocean heat uptake will aid in the comparison and interpretation of the CMIP5 and CMIP6 suite of models.

Here we investigate the effect of vertical and horizontal resolution on the uptake of heat and momentum throughout the Southern Ocean using a global ocean-sea-ice model with an imposed idealized warming scenario. We begin with a description of the model, forcing and methodology (§2), present analysis of how the surface forcing changes with model resolution (§3.1), and then examine the response of the Southern Ocean to an imposed thermal atmospheric perturbation (§3.2). Our perturbation simulations reproduce the characteristic distribution of additional heat uptake and storage (e.g. Armour et al., 2016), which, following Llovel \&3 Terray (2016), we examine in terms of changes in the wind stress curl field, with particular attention on the location of the zero wind stress curl in isopycnal space. These findings are discussed (§4), as well as their implications for Earth's climate and future modelling efforts.

\section{Model \& Methodology}

\subsection{Model Configurations \&3 Forcing}

We use two configurations of the Australian Community Climate and Earth System Simulator (ACCESS) suite of global ocean-sea-ice models: ACCESS-OM2 and ACCESS-OM2-025, which are nominally $1^{\circ}$ and $0.25^{\circ}$ horizontal resolutions, respectively. These configurations have been developed by the Consortium for Ocean-Sea-Ice Modelling in Australia (COSIMA) 
so as to be as consistent as possible to permit direct comparison across resolutions (Kiss et al. , 2019). The ACCESS-OM2 suite of global ocean-sea-ice models use the Modular Ocean Model version 5.1 (MOM5.1; Griffies , 2012) with a $z^{*}$ generalized vertical coordinate, and the Community Ice CodE version 5 (CICE5; Hunke et al., 2015). For the ACCESS-OM2 configuration, four different vertical grids of varying resolutions are employed here (see Table 1 and Stewart et al. , 2017), ranging from a relatively-coarse 50-level grid with $10 \mathrm{~m}$ grid spacing at the surface (GFDL50), to a higher-resolution 135-level grid with $1 \mathrm{~m}$ grid spacing at the surface (KDS135). For the ACCESS-OM2025 configuration, two of these vertical grids are used; the relatively-coarse GFDL50 grid, and a higher-resolution 75-level grid with $1.1 \mathrm{~m}$ grid spacing at the surface (KDS75).

Both the GFDL50 and KDS75 vertical grids were developed specifically for use with the generalized $z^{*}$ vertical coordinate of MOM5. For the GFDL50 vertical grid; when the ocean is at rest, the vertical grid spacing of the uppermost cell is $10 \mathrm{~m}$ thick. The vertical grid spacing gradually and smoothly increases with depth to $\sim 20 \mathrm{~m}$ grid spacing by $\sim 200 \mathrm{~m}$ depth, and rapidly increasing to $\sim 200 \mathrm{~m}$ grid spacing by $\sim 2 \mathrm{~km}$ deep. In the case of the KDS75, the vertical grid spacing follows an hyperbolic tangent to increase smoothly with depth from $1.1 \mathrm{~m}$ thick at the surface through $\sim 150 \mathrm{~m}$ at $\sim 2 \mathrm{~km}$, to $\sim 200 \mathrm{~m}$ at $\sim 6 \mathrm{~km}$ deep; the KDS75 is objectively-constructed so as maximise the regions where the baroclinic mode-2 dynamics are permitted (see Stewart et al. , 2017). Note that for the purposes of this study the key difference between these two vertical grids is the resolution at the ocean surface; $10 \mathrm{~m}$ for GFDL50 and 1.1m for KSD75.

The sub-grid parameterisations for under-represented variability of Gent \& McWilliams (1990) (GM) and Redi (1982) are used for the ACCESS-OM2 simulations. The GM diffusivities are locally scaled in accordance with the ratio of local horizontal grid spacing to the first baroclinic Rossby radius, as suggested by Hallberg (2013), through the ranges of $50-600 \mathrm{~m}^{2} \mathrm{~s}^{-1}$, with the Redi coefficient globally constant at $600 \mathrm{~m}^{2} \mathrm{~s}^{-1}$. The K-profile parameterisation (KPP; Large et al. , 1994), used for the vertical diffusion of tracer and momentum in the surface boundary layer and unstably-stratified occurrences in the interior (i.e., convection is parameterised as an enhanced vertical diffusivity), operates in the simulations at both horizontal resolutions.

The models are initialized with temperature and salinity from the World Ocean Atlas 2013; these consist of the January ocean state above $1500 \mathrm{~m}$, and the boreal winter average state below 1500m (WOA13; Locarnini et al. , 
2013; Zweng et al., 2013). Surface forcing is a repeating year taken from the high-resolution, self-consistent Japanese 55-year atmospheric reanalysis dataset for driving ocean-sea-ice models (JRA55-do Tsujino et al., 2018). The JRA55-do offers atmospheric state, radiation and precipitation forcing fields at 3-hourly, $\sim 55 \mathrm{~km}$ resolution, as well as daily runoff fields that include solid and liquid runoff from Greenland (from Bamber et al., 2012) and Antarctica (from Depoorter et al., 2013). The repeated year forcing period is 1st May 1984 - 30th April 1985, referred to as RYF8485. In practice, the RYF8485 period runs from 1st January 1985 to 31st December 1984 with a sudden transition from 30th April 1985 back to 1st May 1984. The date for this transition is chosen so as to be at a time of year with low synoptic variability at high latitudes and minimal deep water formation and convection, thereby minimising any disturbances arising from the step change in forcing. The justification for this period and forcing methodology is given in Stewart et al. (in prep.); in essence, the RYF8485 is a quasi-climatological 12-month period, with neutral values for all major climate indices. This repeated year forcing allows for an extended period of model adjustment from the initial condition so as to gauge model drift and long-term equilibration, and to serve as control simulations for comparison with perturbation simulations. Surface salinity is restored to a monthly climatology developed from WOA13, and the restoring timescale is adjusted according to the vertical resolution at the ocean surface such that the piston velocity of all simulations is $50 \mathrm{~m}$ per 300 days.

The perturbation to the RYF8485 forcing is the globally-uniform increases of both surface air temperature and downward longwave radiation, with the remaining RYF8485 forcing fields unaltered. These increases are $+1.5^{\circ} \mathrm{C}$ for surface air temperature and $+8 \mathrm{~W} / \mathrm{m}^{2}$ for downward longwave radiation, selected to be representative of the CMIP5 multimodel mean responses in these fields under the Representative Concentration Pathway 4.5 (RCP4.5) scenario of moderate greenhouse gas emissions (see Fig. 2 of Snow et al., 2016); here we refer to these perturbed forcings as RYF8485-RCP45. The idealized nature of this globally-uniform thermal perturbation allows for a direct comparison with the control simulations to assess excess heat uptake by the ocean.

\subsection{Methodology \& Analysis}

All control simulations are initialized from rest with the WOA13 hydrography. The ACCESS-OM2 and ACCESS-OM2-025 control simulations are run for 590 and 200 years, respectively, with the RYF8485 forcing. The 


\begin{tabular}{|c|c|c|c|c|c|c|}
\hline $\begin{array}{c}\text { Configuration } \\
\text { Reference }\end{array}$ & $\begin{array}{c}\text { Horizontal } \\
\text { Grid }\end{array}$ & $\begin{array}{l}\text { Vertical } \\
\text { Levels }\end{array}$ & $\begin{array}{l}\text { Thickness } \\
\text { at Surface }\end{array}$ & $\begin{array}{l}\text { Start } \\
\text { Year }\end{array}$ & $\begin{array}{c}\text { Control } \\
\text { Duration }\end{array}$ & $\begin{array}{c}\text { Perturbation } \\
\text { Duration }\end{array}$ \\
\hline GFDL50 & $1^{\circ}$ & 50 & $10 \mathrm{~m}$ & -300 & 590 & 290 \\
\hline KDS50 & $1^{\circ}$ & 50 & $2.3 \mathrm{~m}$ & -300 & 590 & 290 \\
\hline$K D S 75$ & $1^{\circ}$ & 75 & $1.1 \mathrm{~m}$ & -300 & 590 & 290 \\
\hline KDS135 & $1^{\circ}$ & 135 & $1.0 \mathrm{~m}$ & -300 & 590 & 290 \\
\hline GFDL50-025 & $0.25^{\circ}$ & 50 & $10 \mathrm{~m}$ & -100 & 200 & 50 \\
\hline KDS75-025 & $0.25^{\circ}$ & 75 & $1.1 \mathrm{~m}$ & -100 & 200 & 50 \\
\hline
\end{tabular}

Table 1: ACCESS-OM2 configurations. The start years are relative to the addition of the perturbation. The four configurations in bold form the basis of the comparison from $\S 3.1 .2$ onwards.

model states of the ACCESS-OM2 control simulations after 300 years, and after 100 years for ACCESS-OM2-025, are used to spin off perturbation simulations with the RYF8485-RCP45 forcing. The perturbation simulations for ACCESS-OM2 and ACCESS-OM2-025 are run for 290 and 50 years, respectively, and in parallel with their respective control simulations, allowing for the direct comparison of the perturbation-control differences between the various configurations. For ease of this comparison, we define model time relative to the time of perturbation, so that the ACCESS-OM2 and ACCESS-OM2-025 control simulations begin at model year -300 and -100 , respectively, with all perturbation simulations beginning at model year 0 . Considering the idealized nature of the imposed perturbation, particularly the lack of climate feedbacks on the atmospheric forcing, we focus our analysis on the initial response of the model at a time that is both long enough since perturbation to have an attributable signal, yet early enough that we can be sure the models are still in the same climate regime. So whilst the perturbation simulations are extended for nearly 3 centuries in the case of ACCESS-OM2, and 50 years for ACCESS-OM2-025, we focus on the 4th decade after the addition of the perturbation (model years 30-40).

The analysis is performed and presented in two parts. We first compare the surface forcings (of both heat flux and momentum transfer) of the simulations to assess the sensitivity to horizontal and vertical resolutions. This comparison involves globally- and zonally-averaged diagnostics, focusing on the differences between each configuration in the control state, and inferring the thermal responses we can expect from the perturbation simulations. We then compare these thermal responses, concentrating on the upper $2 \mathrm{~km}$ of the 

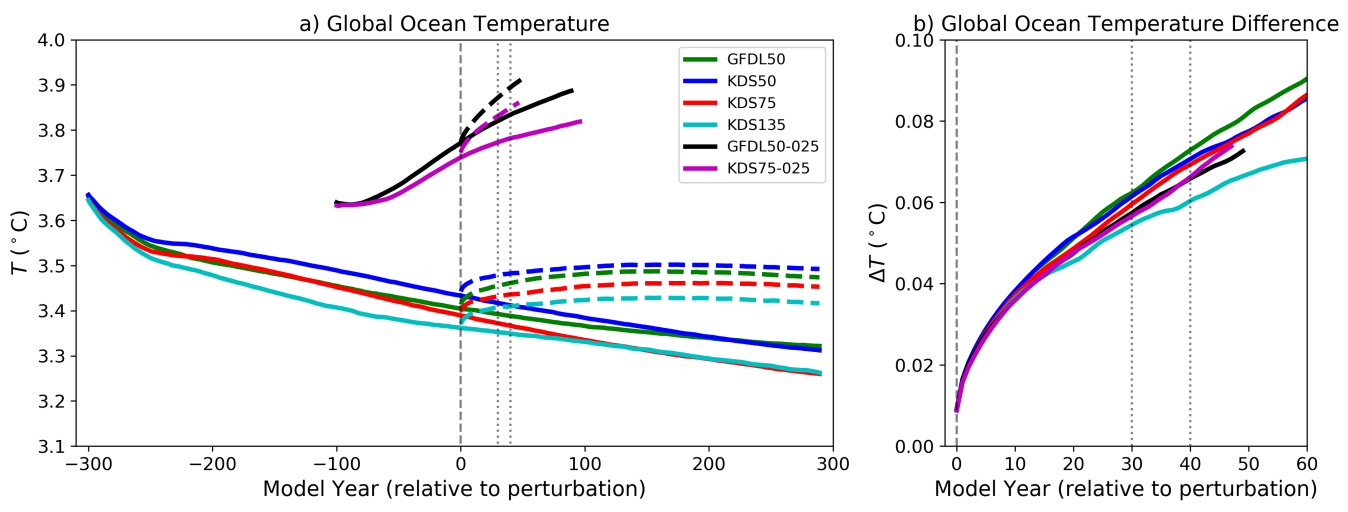

Figure 1: (a) Timeseries of the global mean ocean temperature for the control (solid) and RCP45 perturbation (dashed) simulations. The vertical dashed line indicates model year 0 when the perturbation is imposed. (b) Timeseries of the global mean temperature difference between the RCP45 perturbation simulations and their respective control simulation. The vertical dotted lines indicate the model years 30-40, the period of focus for much of the subsequent analysis.

Southern Ocean south of $35^{\circ} \mathrm{S}$, and the model configurations that have common vertical grids at both horizontal resolutions (GFDL50 and KDS75). This analysis extends from traditional spatial coordinates into isopycnal space, with a particular emphasis on identifying the isopycnals that outcrop near the latitude of zero wind stress curl.

\section{Results}

\section{Global Mean Ocean Temperature}

The global mean ocean temperature for the ACCESS-OM2 control simulations exhibit a general cooling trend throughout the duration of the runs (Fig. 1a). This cooling rate is initially $\mathrm{O}(0.01)^{\circ} \mathrm{C} /$ decade for the first century, and decreases to roughly half that for the remainder of the simulations. The cooling drift reflects an ongoing, gradual adjustment of the deep and abyssal waters from the initial hydrography. For these ACCESS-OM2 simulations, the global mean ocean temperature shows no obvious sensitivity to the vertical resolutions tested here.

In contrast to the $1^{\circ}$ cases, the ACCESS-OM2-025 control simulations exhibit steady warming trends of $\sim 0.15^{\circ} \mathrm{C} /$ decade for the duration of the simulations. Again, the drift reflects a continued adjustment of the deep and 
abyssal waters from the initial hydrography. The warming drift is reduced by $\sim 30 \%$ when vertical resolution is enhanced, but this reduced warming for ACCESS-OM2-025 isn't conclusive with only the two vertical grids examined here.

The addition of the RCP45 perturbation acts to increase the global mean ocean temperature (dashed lines in Fig. 1a). The difference in global mean ocean temperatures between the perturbation and control simulations shows the warming to initially be on the order of $0.05^{\circ} \mathrm{C}$ per decade before adjusting to $0.01^{\circ} \mathrm{C}$ per decade, for an increase of $0.1^{\circ} \mathrm{C}$ for the first 50 years (Fig. $1 \mathrm{~b}$ ). By way of comparison, this global ocean warming is approximately half the rate of that for the ACCESS Coupled Model versions (ACCESS1.0 and ACCESS1.3) contributed to the CMIP5 under the RCP4.5 scenario (Marsland et al. , 2013). This bulk thermal response over the first 5 decades to the perturbation exhibits no strong sensitivity to vertical or horizontal resolutions, despite the model drift in the $1^{\circ}$ and $0.25^{\circ}$ control simulations being of different signs. This result indicates that the initial response is surface-dominant, such that the convection-dominated deep ocean adjustment (which is responsible for the longterm drift in the control simulation) continues in the perturbation simulations. In addition, these consistent and predictable responses suggest the global ocean state of the perturbation and control simulations remain comparable for at least 50 years.

\subsection{Surface Forcing \\ 3.1.1. Control Simulations}

A comparison of the zonally-averaged Southern Ocean surface heat fluxes (diagnosed by the ocean model) shows that the latitudinal structure is sensitive to the horizontal resolution, but largely insensitive to the vertical resolution tested here (Fig. 2a). Likewise, the upper $10 \mathrm{~m}$ average ocean speed depends on horizontal resolution, with both ACCESS-OM2-025 cases exhibiting higher speeds between $45-55^{\circ} \mathrm{S}$ (Fig. 2b), but is insensitive to vertical resolution. There is, however, a sensitivity to vertical resolution in the ocean surface speed $\left(\boldsymbol{u}_{\boldsymbol{o}}\right.$; Fig. 2c), with the surface speed increasing as the vertical grid spacing of the uppermost cell decreases; here from 10m thick (GFDL50) through $2.3 \mathrm{~m}$ (KDS50) to $\sim 1 \mathrm{~m}$ thick (KDS75 and KDS135). This result can be understood by considering the momentum transfer between the atmosphere and ocean; given the same variable wind field, the decreased ocean mass of thinner surface cells are able to accelerate and respond to the wind variability more readily than thicker surface cells. For the $45-55^{\circ} \mathrm{S}$ latitude 

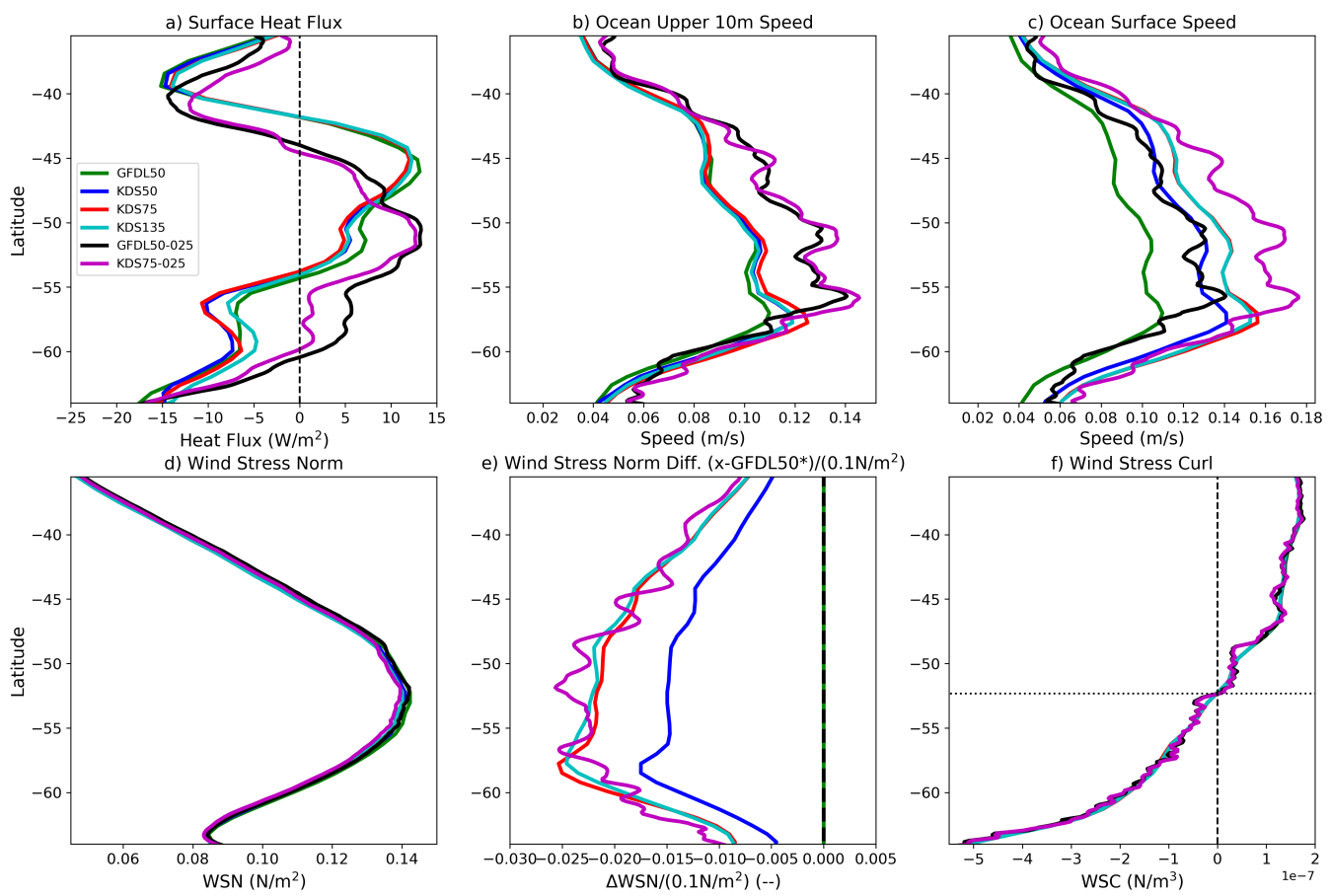

Figure 2: The model year 30-40 means of the zonal averages of the (a) surface heat flux, (b) upper $10 \mathrm{~m}$ ocean speed, (c) ocean surface speed, (d) the wind stress norm, (e) the difference in wind stress norm from the respective GFDL50 simulation (normalized by a nominal value of wind stress norm, $0.1 \mathrm{~N} / \mathrm{m}^{2}$ ), and (f) the wind stress curl. The horizontal dotted line in (f) indicates the latitude where the zonally-averaged wind stress curl passes through zero.

band there is a $>30 \%$ increase in ocean surface speed for simulations using vertical grids with surface resolutions of $\sim 1 \mathrm{~m}$ (KDS75 and KDS135) relative to their $10 \mathrm{~m}$ counterparts (GFDL50).

Ocean models typically use the ocean surface speed to dynamically calculate the sensible heat and evaporative fluxes, as well as the wind stresses exerted onto the ocean surface, by way of the relative difference between the wind and ocean surface velocities. In the cases of sensible heating and evaporation, the fluxes have linear dependences on both the relative difference between the wind and ocean surface velocities, and on the ocean-air temperature difference and specific humidity of the atmosphere, respectively. For wind stress, however, the dynamic forcing exerted onto the ocean has a quadratic dependence on the relative difference between the wind and ocean 
surface velocities. Given the sensitivity of ocean surface speed to the vertical resolution at the ocean surface, we should expect the wind stress $\left(\boldsymbol{\tau} ; \mathrm{N} / \mathrm{m}^{2}\right)$ to also exhibit a sensitivity to the vertical resolution at the ocean surface.

From Pacanowski (1987), the wind stress exerted on the ocean surface is computed as,

$$
\boldsymbol{\tau}=C_{d} \rho_{a}\left|\boldsymbol{u}_{\boldsymbol{a}}-\boldsymbol{u}_{\boldsymbol{o}}\right|\left(\boldsymbol{u}_{\boldsymbol{a}}-\boldsymbol{u}_{\boldsymbol{o}}\right),
$$

where $C_{d}$ is the drag coefficient, $\rho_{a}$ is the density of air, and $\boldsymbol{u}_{\boldsymbol{a}}$ is the velocity of the atmospheric winds. Figure $2 \mathrm{~d}$ shows the zonal average of the wind stress norm $\left(\mathrm{N} / \mathrm{m}^{2}\right)$, calculated as,

$$
\|\boldsymbol{\tau}\|=\sqrt{\tau_{x}^{2}+\tau_{y}^{2}},
$$

where $\tau_{x}$ and $\tau_{y}$ are the zonal and meridional components of the model diagnosed wind stresses, respectively. The difference between the wind stress norm of a given simulation and that of the corresponding GFDL50 simulation is shown in Figure 2e, normalized by a nominal value of wind stress, $0.1 \mathrm{~N} / \mathrm{m}^{2}$. Simulations with thinner surface cells experience a reduced wind stress, as the increased ocean surface speed is closer the imposed wind speed. For the simulations with vertical resolutions of $\sim 1 \mathrm{~m}$ at the surface (KDS75 and KDS135), the reduction in wind stress is on the order of $2.5 \%$ between $45-55^{\circ} \mathrm{S}$. These reductions in wind stress are substantial, especially considering that each simulation is forced with the same atmospheric wind fields, and that the differences in the wind stress norm vary systematically with the vertical resolution at the ocean surface.

Wind stress drives vertical velocities (Ekman pumping, written as $w_{E k}$ ) through the wind stress curl $\left(\mathrm{N} / \mathrm{m}^{3}\right)$,

$$
w_{E k}=\frac{\nabla \times \boldsymbol{\tau}}{\rho_{0} f},
$$

which is of greater dynamical importance to vertical flow than the wind stress itself. In the Southern Hemisphere, regions of negative wind stress curl are upwelled (positive $w_{E k}$ ), while positive wind stress curl results in downwelling (negative $w_{E k}$ ). For all the JRA55-RYF8485 forced simulations examined here, the zero crossing of the zonally-averaged wind stress curl is at $52^{\circ} \mathrm{S}$ (Fig. 2f).

The distributions of Southern Ocean wind stress curl for the GFDL50 simulations are shown in Figure 3a,c. The meridional structure indicated by Figure $2 \mathrm{f}$ is evident; the wind stress curl tends to be positive north of $\sim 45^{\circ} \mathrm{S}$ 
and negative south of $\sim 60^{\circ} \mathrm{S}$, with the exception of Antarctic shelf regions (especially in ACCESS-OM2-025). However, unlike Figure $2 \mathrm{f}$ suggests, the transition from positive to negative wind stress curl is gradual and varies with longitude; this variation is especially strong for ACCESS-OM2-025, where the transition region is populated with relatively intense and localised occurrences of positive and negative wind stress curl. Values of the mean wind stress curl for regions representative of the Indian, Pacific and Atlantic basins are listed in Table 2.

By way of comparison, the differences in wind stress curl between the GFDL50 simulations and their respective KDS75 simulations are shown Figure 3b,d. For ACCESS-OM2 (Fig. 3b), the wind stress curl difference is generally negative to the north of $\sim 55^{\circ} \mathrm{S}$ and generally positive to the south; the differences in wind stress curl for the three basins are listed in Table 2. This pattern suggests that for regions where the wind stress curl are generally positive (north of $\sim 52^{\circ} \mathrm{S}$ ), the wind-driven downwelling in the KDS75 simulation will be relatively weaker than that of the GDFL50 simulation.

Patterns in the wind stress curl difference for ACCESS-OM2-025 are less obvious, as the distribution is dominated by mesoscale features, particularly at higher latitudes. The strength of these mesoscale features are weaker in regions where the wind stress curl is generally positive, and tending to intensify to the south as the wind stress curl transitions to negative, especially in the Indian and Pacific basins. Overall, the wind stress curl difference between the ACCESS-OM2-025 simulations is generally negative where the wind stress curl is positive, and generally positive (with intense and localised regions of negative) where the wind stress curl transitions through zero to negative; again, this is reflected in the calculated differences of wind stress curl for the three regions (Tab. 2). These differences in wind stress curl suggest the simulations with coarse surface vertical resolution will tend to have enhanced wind-driven vertical motions.

The upwelling and downwelling of wind-driven Ekman flows are typically considered in terms of vertical motion, but their effect on interior circulation is to drive residual motion along isopycnals (e.g., Doddridge et al. , 2016). As such, it makes sense to examine the wind stress curl in isopycnal space; here we use $\sigma_{2}$, the potential density referenced to 2000dbar. For this analysis, we bin the surface ocean south of $35^{\circ} \mathrm{S}$ in $\sigma_{2}$-space and calculate the average wind stress curl for each $\sigma_{2}$ bin. Figure 4a,c shows distributions of the average wind stress curl by surface $\sigma_{2}$ for model years 30-40 for the GFDL50 simulations. These are the same data depicted in Figure 3a,c only now shown in $\sigma_{2^{-}}$ 

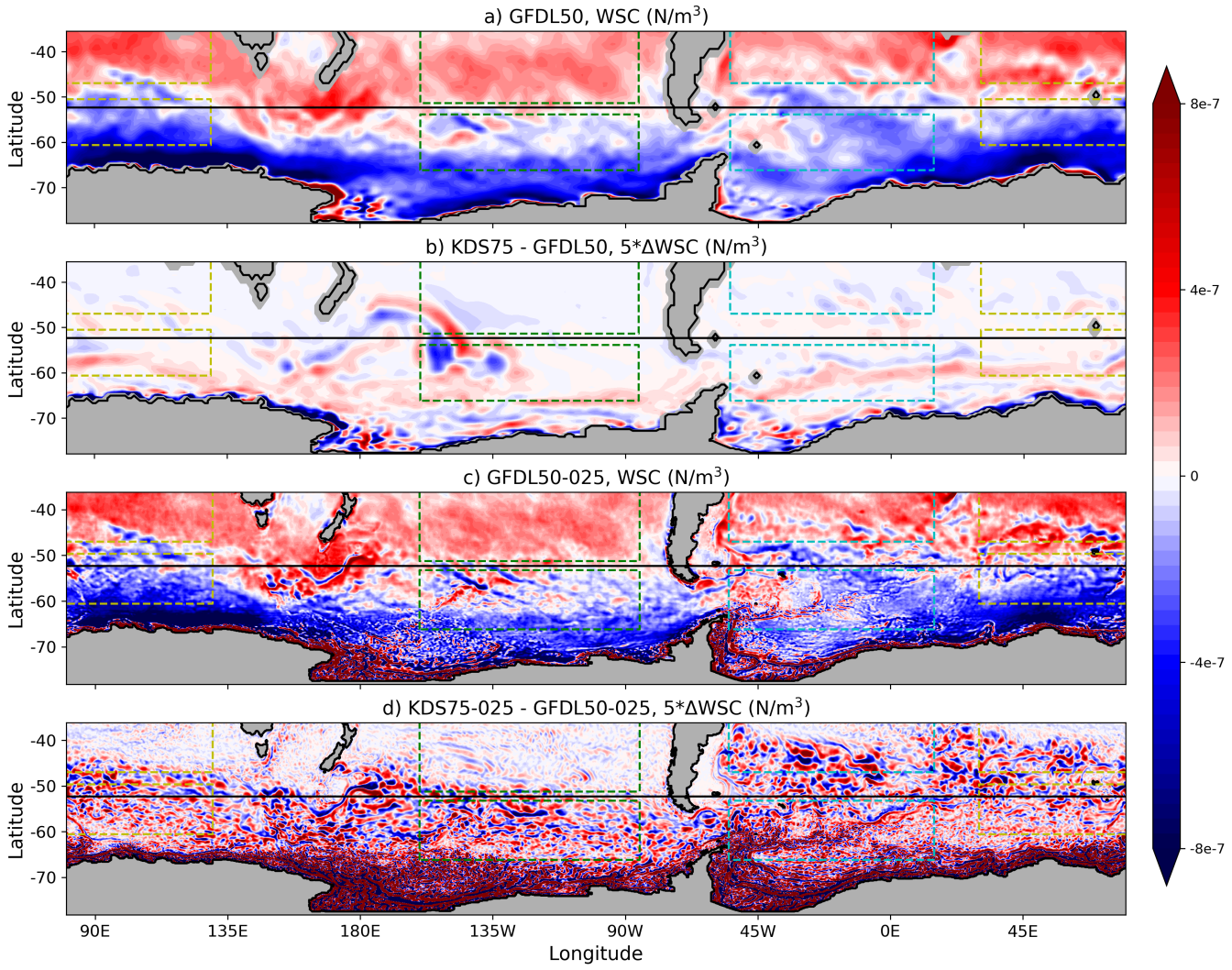

Figure 3: The Southern Ocean distributions of model years 30-40 average wind stress curl (WSC) for the (a) GFDL50 and (c) GFDL50-025 simulations, and the difference between these and their respective KDS75 simulations $(\mathrm{b}, \mathrm{d})$. The latitude of the zero wind stress curl is indicated by the solid line, and mean values of WSC and $\triangle \mathrm{WSC}$ in the dashed regions are listed in Table 2. 


\begin{tabular}{c||c|c|c||c|c|c}
$\begin{array}{c}\text { Region } \\
\text { Geography } / \sigma_{2}\end{array}$ & GFDL50 & KDS75 & $\begin{array}{c}1^{\circ} \text { diff. } \\
(\%)\end{array}$ & $\begin{array}{c}\text { GFDL50 } \\
-025\end{array}$ & $\begin{array}{c}\text { KDS75 } \\
-025\end{array}$ & $\begin{array}{c}0.25^{\circ} \\
\text { diff. }(\%)\end{array}$ \\
\hline \hline Nth. Indian & 1.92 & 1.89 & $\mathbf{- 1 . 4 4}$ & 1.91 & 1.89 & $\mathbf{- 1 . 4 8}$ \\
Sth. Indian & -2.10 & -2.07 & $\mathbf{1 . 4 9}$ & -1.98 & -1.95 & $\mathbf{1 . 8 1}$ \\
\hline Nth. Pacific & 1.44 & 1.41 & $\mathbf{- 1 . 5 3}$ & 1.45 & 1.43 & $\mathbf{- 1 . 6 4}$ \\
Sth. Pacific & -0.98 & -0.97 & $\mathbf{1 . 1 6}$ & -0.94 & -0.94 & $\mathbf{0 . 7 2}$ \\
\hline Nth. Atlantic & 1.31 & 1.28 & $\mathbf{- 2 . 1 7}$ & 1.30 & 1.29 & $\mathbf{- 0 . 8 2}$ \\
Sth. Atlantic & -1.28 & -1.26 & $\mathbf{1 . 6 1}$ & -1.23 & -1.21 & $\mathbf{1 . 1 9}$ \\
\hline \hline Light Indian & 1.02 & 1.42 & $\mathbf{1 6 . 5 7}$ & 1.52 & 1.69 & $\mathbf{0 . 0 3}$ \\
Dense Indian & -1.52 & -1.41 & $\mathbf{9 . 7 5}$ & -1.16 & -1.31 & $\mathbf{- 1 6 . 4 6}$ \\
\hline Light Pacific & 0.62 & 0.91 & $\mathbf{2 4 . 6 3}$ & 1.31 & 1.38 & $\mathbf{4 . 0 0}$ \\
Dense Pacific & -0.88 & -0.83 & $\mathbf{9 . 0 0}$ & -0.86 & -0.86 & $\mathbf{0 . 7 2}$ \\
\hline Light Atlantic & 0.87 & 1.00 & $\mathbf{1 1 . 2 2}$ & 1.12 & 1.18 & $\mathbf{5 . 0 2}$ \\
Dense Atlantic & -0.64 & -0.62 & $\mathbf{5 . 4 0}$ & -0.54 & -0.78 & $\mathbf{- 3 0 . 7 2}$ \\
\hline \hline
\end{tabular}

Table 2: Values of the mean wind stress curl $\left(\mathrm{N} / \mathrm{m}^{3}\right)$ in simulations with GFDL50 and KDS75 for the regions depicted in Figures 3 (upper 3 rows) and 4 (lower 3 rows). The KDS75-GFDL50 difference is given as a percentage of their average. For northern/light regions where the wind stress curl is positive, a negative difference (indicated in blue) suggests the KDS75 will experience less wind-driven downwelling. For southern/dense regions where the wind stress curl is negative, a positive difference (indicate in red) suggests the KDS75 will experience less wind-driven upwelling. 
longitude space. Ekman downwelling occurs on isopycnals where the wind stress curl is positive, and Ekman upwelling where it is negative; these regions are separated by the isopycnal at the location of the zero wind stress curl, which is denoted here as $\sigma_{2}^{0}$. For the GFDL50 control simulation, the zonalaverage of $\sigma_{2}^{0}=1035.85 \mathrm{~kg} / \mathrm{m}^{3}$, and $\sigma_{2}^{0}=1035.75 \mathrm{~kg} / \mathrm{m}^{3}$ for GFDL50-025. Values for the mean wind stress curl in the "light" and "dense" regions of each major basin (indicated by the dashed regions) are listed in Table 2; these are positive and negative for the light and dense regions, respectively. While there appears much in common between the wind stress curl analysis in Eulerian and $\sigma_{2}$-space, one important difference is the increased zonal coherency of the isopycnal of the zero wind stress curl $\sigma_{2}^{0}$ relative to that of the latitude of zero wind stress curl. This is particularly the case in the Indian and Pacific basins, where the increased zonal coherency is evidenced by the sharper transition between negative and positive wind stress curl and greater consistency in the isopycnal at which this transition occurs.

The difference in wind stress curl on surface $\sigma_{2}$ between the GFDL50 simulations and the KDS75 simulations with relatively thinner surface cells are shown in Figure 4b,d. Again, these are the same data depicted in Figure $3 \mathrm{~b}, \mathrm{~d}$ mapped onto $\sigma_{2}$-longitude space. It is apparent that the intensity of the wind stress curl differences have increased relative to the spatial distribution comparisons in Figure 3. This enhanced variability is to be expected; in Eulerian space with a spatially-fixed wind field, the only way the wind stress curl can change is by a change in ocean surface speed (e.g., see Eqns. 1 and 3). In $\sigma_{2}$-space, however, the isopycnals are able to move relative to the wind field, granting the wind stress curl on $\sigma_{2}$ an additional degree of freedom. The strongest features in Figure $3 \mathrm{~b}, \mathrm{~d}$ remain evident in $\sigma_{2}$-longitude space, as well as the relatively reduced differences in regions of predominantly positive wind stress curl, especially for ACCESS-OM2-025. Also apparent in ACCESS-OM2-025 is the variability in the Atlantic extending to isopycnals of $\sigma_{2}=1034.5 \mathrm{~kg} / \mathrm{m}^{3}$, which is less-dense than the zonal average zero wind stress curl $\sigma_{2}^{0}$ of $1035.75 \mathrm{~kg} / \mathrm{m}^{3}$. Importantly, the calculated differences for the light and dense regions of the major basins differ from those calculated for the corresponding north and south regions. Of note are the $16 \%$ and $30 \%$ differences in wind stress curl in the dense Indian and Atlantic regions of ACCESS-OM2-025, respectively, indicating that the KDS75-025 simulation will have enhanced upwelling of denser waters in these regions relative to the GFDL50-025 simulation. However, considering the relatively noisy distributions of the wind stress curl fields of the ACCESS-OM2-025 simulations, 


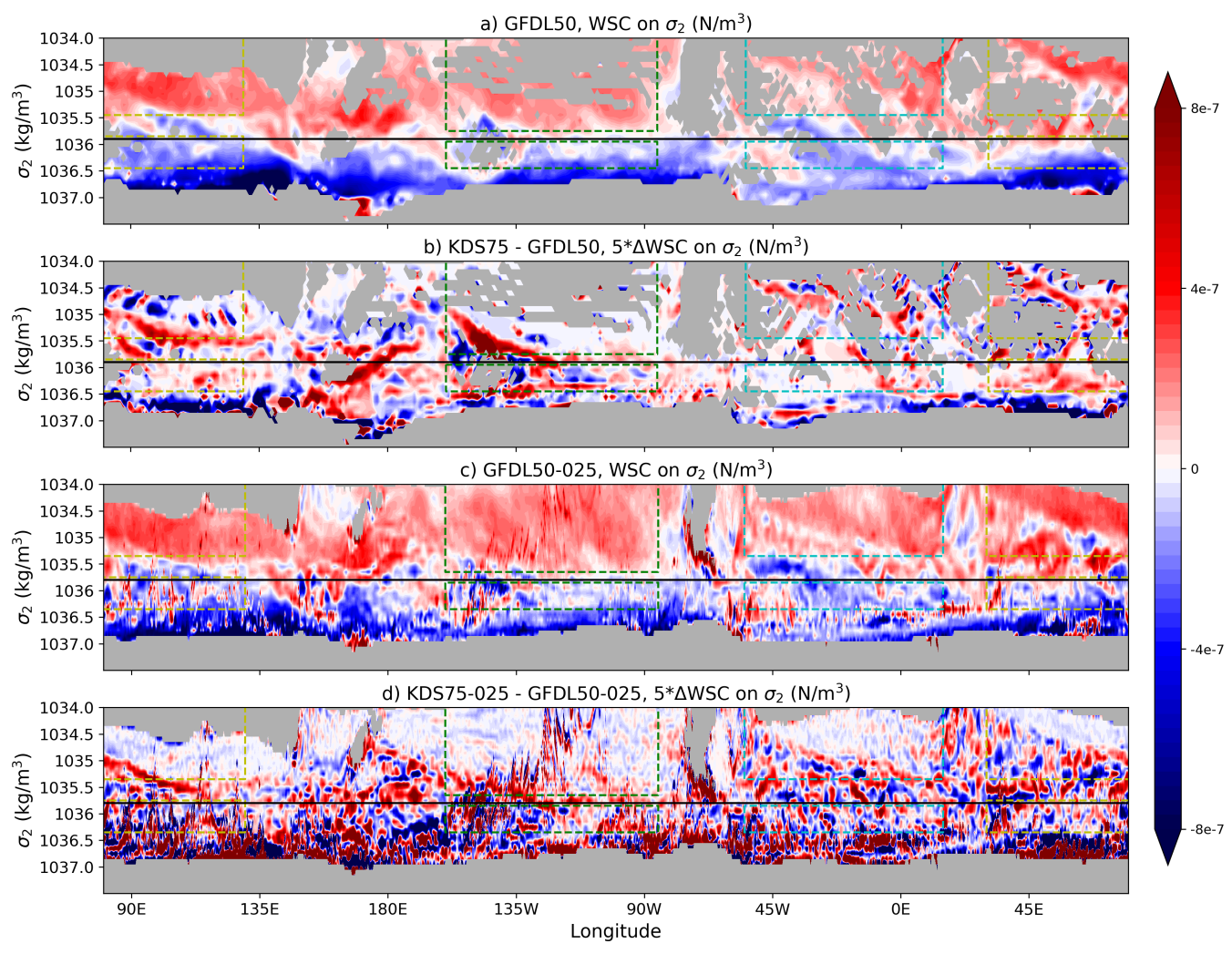

Figure 4: As for Figure 3, except transformed into $\sigma_{2}$-longitude space. The grey regions are isopycnals that do not outcrop (and hence have no value of wind stress curl) at that longitude. The zonally-averaged isopycnal of zero wind stress curl $\sigma_{2}^{0}$ is indicated by the solid line, and mean values of wind stress curl and $\Delta \mathrm{WSC}$ in the dashed regions are listed in Table 2. 
especially in the southern/dense Indian and Atlantic Ocean (e.g., Figs. 3c,d, $4 \mathrm{c}, \mathrm{d})$, these differences may be sensitive to the selection of the region extent.

\subsection{2. $R C P 45$ Perturbation Simulations}

The RCP45 perturbation imposed here is purely thermal, consisting of idealized, globally-uniform increases in both the atmosphere temperature $\left(+1.5^{\circ} \mathrm{C}\right)$ and downwelling longwave radiation $\left(+8 \mathrm{~W} / \mathrm{m}^{2}\right)$ fields. It is important to note that this perturbation is not necessarily a direct increase of the surface heat flux (SHF; W/ $\mathrm{m}^{2}$ ) experienced by ocean model; for example, dynamics in the ocean circulation and associated heat transports and/or redistributions can initiate feedbacks that mitigate SHF changes locally, even resulting in a cooling of certain regions. Figure 5a shows the SHF anomaly $(\triangle \mathrm{SHF} ; \mathrm{RCP} 45$ perturbation minus control) for the KDS75-025 simulations averaged for the model years 30-40; all cases explored here exhibit similar $\triangle \mathrm{SHF}$ distributions and magnitudes, especially for the Southern Ocean, and are consistent with the characteristic distribution reported previously (e.g. Marshall et al., 2015; Armour et al., 2016). The zonal averages of $\Delta \mathrm{SHF}$ for the simulations with the GFDL50 and KDS75 vertical grids are shown in Figure 5b; these show the increased SHF is strongest poleward of $\sim 55^{\circ} \mathrm{S}$, consistent with the findings of previous studies (e.g. Frölicher et al., 2015; Liu et al , 2018). Importantly, there is no evidence of resolution dependence to the SHF for the simulations examined here. The largest increases in SHF occur poleward of the latitude of zonally-averaged zero wind stress curl, however even here the increase in SHF is approximately half that of longwave radiation perturbation. Examining these Southern Ocean SHF anomalies in $\sigma_{2}$-space reveals a sensitivity to horizontal resolution, however the magnitude of the changes in SHF are again smaller than the imposed longwave radiation perturbation (Fig. $5 \mathrm{c}$ ). These relatively weak $\triangle \mathrm{SHF}$ responses suggest that substantial thermal anomalies in the RCP45 perturbation simulations will likely be due to heat redistributions and/or changes in the ocean circulations.

The thermal perturbation of the RCP45 simulations both act to lighten the surface waters of the model ocean, thereby shifting the outcrops of isopycnals poleward. In this way, the imposed wind field, which is not perturbed, operates on relatively lighter surface waters, shifting the distribution of wind stress curl on $\sigma_{2}$ towards less-dense waters (compare Figs. 5d and 5e). Importantly, the isopycnal located at the zero wind stress curl $\sigma_{2}^{0}$ lightens; by year 30-40 of the perturbed simulation, the density of $\sigma_{2}^{0}$ of all simulations 
has decreased by $0.1-0.15 \mathrm{~kg} / \mathrm{m}^{3}$.

The difference in wind stress curl between the perturbation and control simulations on surface $\sigma_{2}$ is shown in Figure 5f. All simulations exhibit a decrease in wind stress curl for isopycnals $\sigma_{2}>1035.2 \mathrm{~kg} / \mathrm{m}^{3}$, suggesting that the RCP45 perturbation simulations will experience,

1. more wind-driven upwelling on isopycnals denser than the zero wind stress curl $\sigma_{2}^{0}$ of their respective controls $\left(>\sigma_{2}^{0, c}\right.$, where the superscript $c$ denotes the $\sigma_{2}^{0}$ of the control simulation);

2. less wind-driven downwelling on isopycnals lighter than their new $\sigma_{2}^{0}$ under the perturbation $\left(<\sigma_{2}^{0, p}\right.$, where the superscript $p$ denotes the $\sigma_{2}^{0}$ of the perturbation simulation); and

3. a range of isopycnals between $\sigma_{2}^{0, p}<\sigma_{2}<\sigma_{2}^{0, c}$ that were downwelled in the control simulations, now upwelled in the perturbation simulations.

These effects are schematically depicted in Figure 6. Taking these effects into consideration, we anticipate the enhanced upwelling of isopycnals denser than the isopycnal at the location of the zero wind stress curl in the RCP45 perturbation simulations will actually result in a subsurface cooling in regions throughout the Southern Ocean. Additionally, the reduced downwelling of isopycnals lighter than the isopycnal at the location of the zero wind stress curl in the RCP45 perturbation simulations will increase the time that these waters are near-surface and exposed to the warmer atmospheric conditions. This concurrent enhanced upwelling and reduced downwelling either side of the isopycnal location of the zero wind stress curl represents a watermass transformation from dense-to-light waters. In $\sigma_{2}$-space, these effects will appear as a light-dense (north-south) dipole of heat increase and decrease centered about the isopycnal of zero wind stress curl.

\subsection{Thermal Response to the RCP 45 Perturbation}

Figure 7 shows the Southern Hemisphere zonal averages of temperature difference in years $30-40$ between the RCP 45 perturbation and control simulations for cases with the GFDL50 and KDS75 vertical grids. The enhanced surface temperature increase is evident in all cases, as is the apparent absence of deep $(>2500 \mathrm{~m})$ temperature changes. The upper ocean temperature increase is strongest between $40-50^{\circ} \mathrm{S}$ and extending to depths nearing $700 \mathrm{~m}$; this response is consistent with that observed and in fully-coupled climate models (e.g., Marshall et al., 2015; Llovel 83 Terray, 2016; Armour et al., 2016), in spite of the idealized perturbation employed here. All simulations 

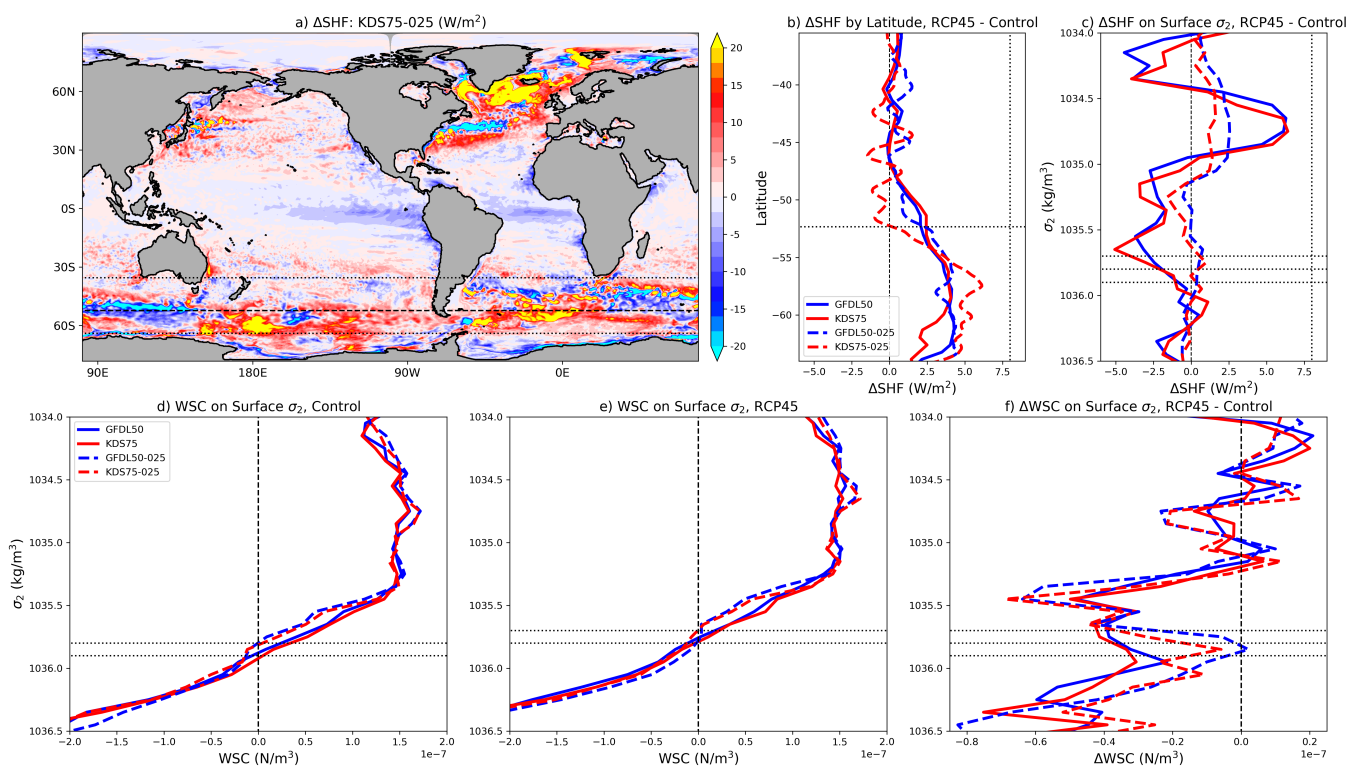

Figure 5: (a) Distribution of surface heat flux anomaly ( $\Delta$ SHF; RCP45 perturbation minus control) of the KDS75-025 case averaged for model years 30-40. The latitude dashed is that of the zero wind stress curl. The latitudes dotted indicate the meridional extent of panel (b), which shows the zonally-averaged $\triangle$ SHF of years 30-40 for the cases with the GFDL50 and KDS75 vertical grids. For reference, the imposed downward longwave radiation perturbation is indicated by the vertical dotted line at $8 \mathrm{~W} / \mathrm{m}^{2}$, as with the latitudinal location of the zero wind stress curl $\left(52^{\circ} \mathrm{S}\right)$. (c) The same $\Delta \mathrm{SHF}$ values as (b), only transformed into surface $\sigma_{2}$ coordinates and zonally averaged. (d,e) The zonally averaged wind stress curl by surface $\sigma_{2}$ for the region south of $35^{\circ} \mathrm{S}$ for the control and RCP45 perturbation simulations, respectively, with their difference shown in (f). For (c-f), the dotted horizontal lines indicate the isopycnal locations of the zero wind stress curls for the relevant simulations. 

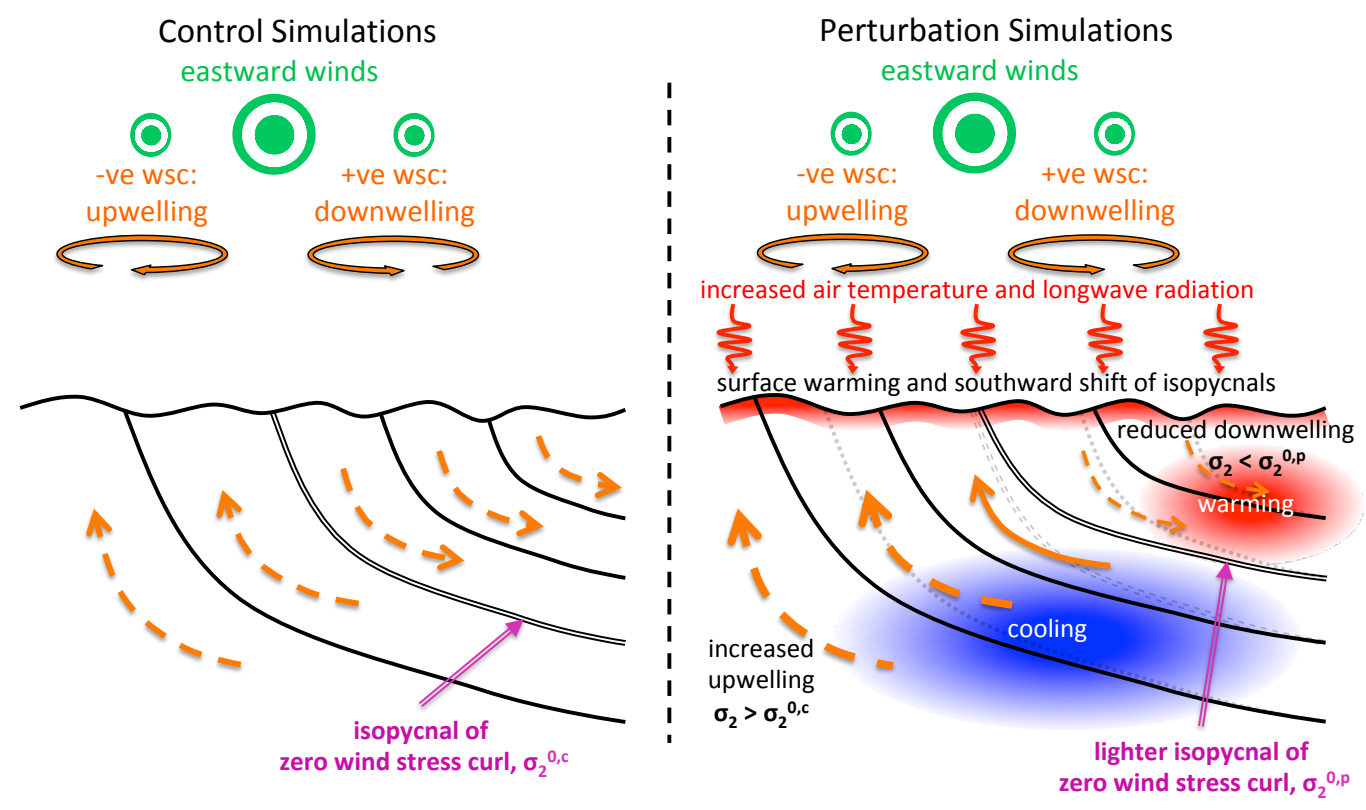

Figure 6: A schematic representation of the expected changes in wind-driven motions along isopycnals between the control and perturbation simulations. 
exhibit a deepening and southward shift of the $\sigma_{2}$ isopycnals, particularly for the $\sigma_{2}=1035.5$ and $1036 \mathrm{~kg} / \mathrm{m}^{3}$ isopycnals, and $\sigma_{2}=1037 \mathrm{~kg} / \mathrm{m}^{3}$ isopycnal for ACCESS-OM2-025 south of $60^{\circ} \mathrm{S}$. The overall distribution of the temperature increase through the upper $1000 \mathrm{~m}$ north of $50^{\circ} \mathrm{S}$ appears relatively insensitive to horizontal and vertical resolution, including isolated patches of temperature decrease in the upper tropics. South of $40^{\circ} \mathrm{S}$, however, the ACCESS-OM2-025 simulations exhibit a temperature decrease for $1036.5<\sigma_{2}<1037 \mathrm{~kg} / \mathrm{m}^{3}$ that extends towards $250 \mathrm{~m}$ depth that is not apparent in ACCESS-OM2. We propose that this decrease in temperature likely results from enhanced upwelling along these isopycnals in these simulations where eddies are partially resolved and augmented with a weak eddy parameterisation. Both simulations with KDS75 display increased thermal anomaly deeper than $\sim 1 \mathrm{~km}$ and south of $60^{\circ} \mathrm{S}$, likely resulting from the decrease in convection due to surface warming; this response is stronger in ACCESS-OM2-025, reflecting the increased role of convection in the $0.25^{\circ}$ model relative to the $1^{\circ}$ model.

The sensitivity of the warming response to the RCP45 perturbation can be better characterised by partitioning the zonally-averaged temperature differences into the major ocean basins (Fig. 8). In all simulations, the response of the Atlantic sector is most unlike the global response, reflecting the leading role of the southern Pacific and Indian Oceans in global ocean heat uptake. The largest impact of horizontal resolution relates to the temperature decrease signal associated with upwelling between $1036.5<\sigma_{2}<1037 \mathrm{~kg} / \mathrm{m}^{3}$ in all basins. This signal is apparent in both ACCESS-OM2-025 simulations, reaching depths shallower than $250 \mathrm{~m}$ in the Atlantic and Indian sectors, and is stronger in the KDS75-025 simulation, as suggested by the relative strength of the wind stress curl in these regions (Tab. 2). In all simulations, the temperature increase of the upper $700 \mathrm{~m}$ in the Atlantic is centered around $40^{\circ} \mathrm{S}$ and $\sigma_{2}=1035.5 \mathrm{~kg} / \mathrm{m}^{3}$, which is relatively northward and on lighter isopycnals than the warming in the Indo-Pacific basins. There is, however, the strongest evidence of a temperature decrease by upwelling in the Atlantic in all simulations, especially KDS75-025. Interestingly, isopycnal $\sigma_{2}=1036.5 \mathrm{~kg} / \mathrm{m}^{3}$ that bounds the strong cold signal in this sector is the only isopycnal to exhibit a northward shift under the perturbation, although the outcrop of this isopycnal has shifted southward. In all simulations, the Indian sector exhibits a temperature increase on isopycnals spanning $1035<\sigma_{2}<1036.5 \mathrm{~kg} / \mathrm{m}^{3}$.

Temperature differences in Eulerian space cannot provide a complete pic- 

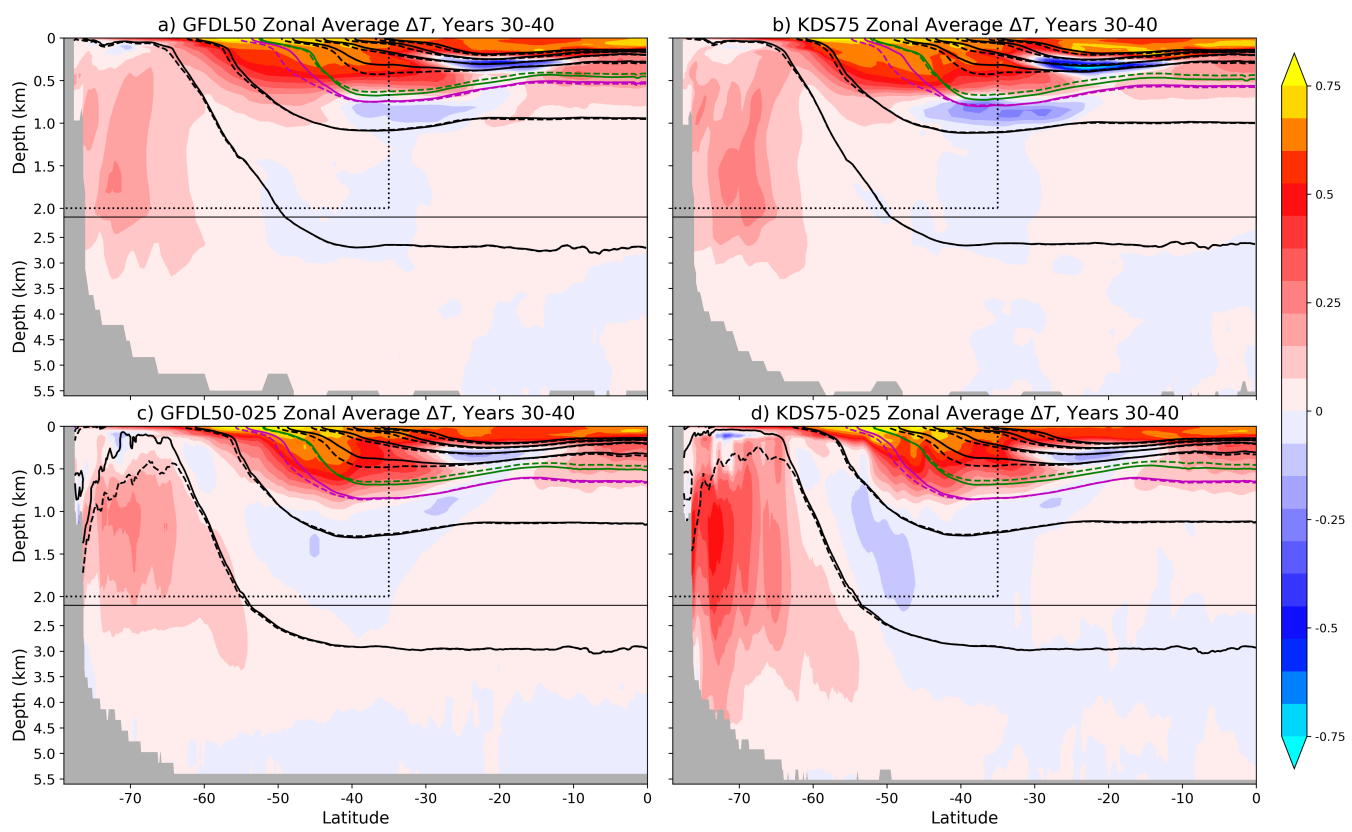

Figure 7: Zonally-averaged temperature difference between the RCP45 perturbation and control simulations for model years $30-40$, for (a) the $1^{\circ}$ simulation with the GFDL50 vertical grid; (b) $1^{\circ}$ simulation with the KDS75 vertical grid; (c) $0.25^{\circ}$ simulation with the GFDL50 vertical grid and (d) $0.25^{\circ}$ simulation with the KDS75 vertical grid. The $\sigma_{2}=1034-1037 \mathrm{~kg} / \mathrm{m}^{3}$ contours are included, at $0.5 \mathrm{~kg} / \mathrm{m}^{3}$ intervals, for the control (solid) and RCP45 perturbation (dashed) simulations, with the $\sigma_{2}=1036 \mathrm{~kg} / \mathrm{m}^{3}$ coloured magenta for reference, and the $\sigma_{2}^{0}$ contoured in green. The dotted lines bound the $2000 \mathrm{~m}, 35^{\circ} \mathrm{S}$ region of interest for subsequent analysis. 

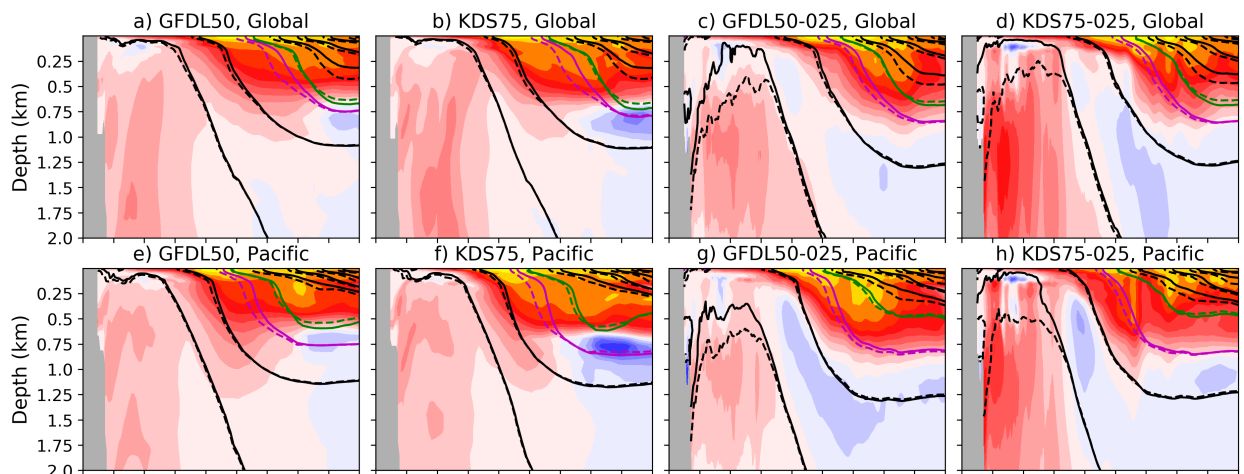

h) KDS75-025, Pacific'
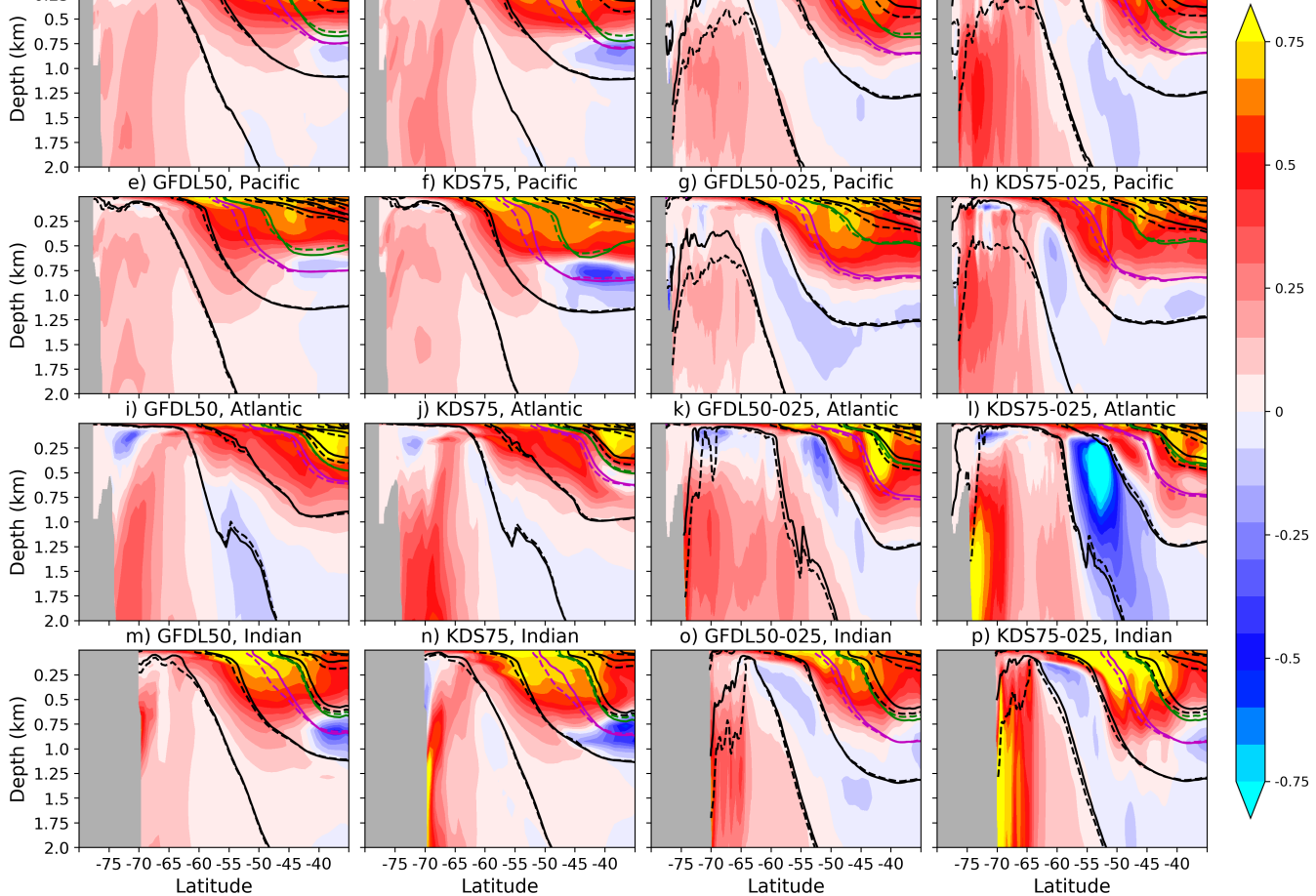

I) KDS75-025, Átlantic
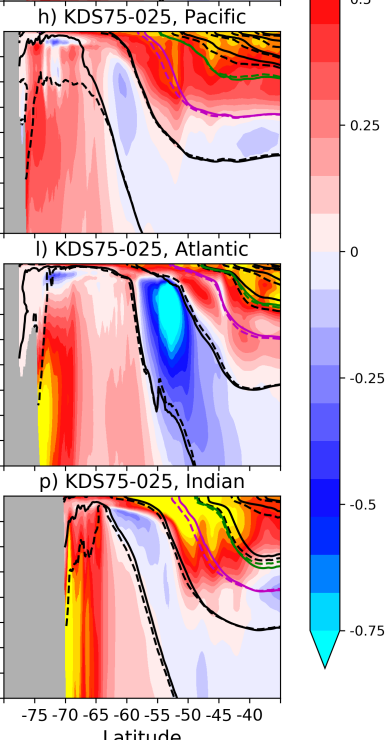

Figure 8: As for Figure 7, focusing on the region bound by $2000 \mathrm{~m}$ and $35^{\circ} \mathrm{S}$, showing the zonal average temperature difference by major ocean basin. Again, the $\sigma_{2}=1034$ $1037 \mathrm{~kg} / \mathrm{m}^{3}$ contours are included, at $0.5 \mathrm{~kg} / \mathrm{m}^{3}$ intervals, for the control (solid) and RCP 45 perturbation (dashed) simulations, with the $\sigma_{2}=1036 \mathrm{~kg} / \mathrm{m}^{3}$ coloured magenta for reference, and the $\sigma_{2}^{0}$ contoured in green. 
ture of ocean heat uptake. A more comprehensive view can be gained by employing frameworks that delineate the movement of isopycnal surfaces and the transformation of watermasses. One such approach is to compare the responses of the meridional overturning streamfunctions in $\sigma_{2}$-latitude space, denoted here as $\Psi(\mathrm{Sv})$. Figure 9a-d shows the differences in Southern Hemisphere overturning streamfunctions, $\Delta \Psi=\Psi^{p}-\Psi^{c}$, between the RCP45 perturbation $\left(\Psi^{p}\right)$ and control simulations $\left(\Psi^{c}\right)$ for cases with the GFDL50 and KDS75 vertical grids. All simulations exhibit an increased overturning of the upper cell of over $5 \mathrm{~Sv}$ in locations between $60-30^{\circ} \mathrm{S}$ and $\sigma_{2}=1035.5-1036.0 \mathrm{~kg} / \mathrm{m}^{3}$ (i.e., spanning the isopycnal locations of zero wind stress curl). These increases in upper cell overturning correspond with a shift in the streamfunction distributions to lighter isopycnals; in Figure 9a-d, these shifts appear as an isopycnal displacement of the upper cell $\Psi$ contours by approximately $0.1-0.15 \mathrm{~kg} / \mathrm{m}^{3}$. This isopycnal shift of the upper overturning cell, which is often referred to as the adiabatic "wind-driven" overturning cell (e.g., Wolfe \& Cessi, 2011), is consistent with the isopycnal shift of the wind stress curl between the RCP45 perturbation and control simulations (e.g., Figs. 5,6). That is, in the RCP45 perturbation simulations, the imposed wind field operates on relatively less-dense surface waters, resulting in a wind-driven overturning circulation of similar magnitude and structure, only shifted towards lighter isopycnals. There is relatively little change in the structure and magnitude of the lower cell overturning northward of $\sim 60^{\circ} \mathrm{S}$.

Examining the overturning streamfunctions in $\sigma_{2}$-latitude space provides a common framework in which we can compare simulations with different vertical grids. Figure 9e,f shows the difference in the overturning responses between the simulations with the KDS75 and GFDL50 vertical grids, $\Delta \Delta \Psi=\Delta \Psi_{K D S 75}-\Delta \Psi_{G F D L 50}$. At both horizontal resolutions, the upper cell overturning of the simulations with the GFDL50 vertical grids is more affected by the RCP45 thermal perturbation than those of the KDS75 vertical grids. This result is consistent with the relatively weaker wind stress and wind stress curl experienced by the KDS75 simulations due to the finer vertical resolution at the ocean surface.

To further delineate the effects of isopycnal movements and watermass transformations, the model output for the region bound by $2000 \mathrm{~m}$ and $35^{\circ} \mathrm{S}$ is binned in $\sigma_{2}$-space, and its total heat content, $Q(\mathrm{~J})$, is calculated as,

$$
Q\left(\sigma_{2}\right)=\sum \sigma_{2} c_{p} T_{\sigma_{2}} V_{\sigma_{2}}
$$

where $c_{p}$ is the specific heat capacity of seawater, and $T_{\sigma_{2}}$ and $V_{\sigma_{2}}$ are the 


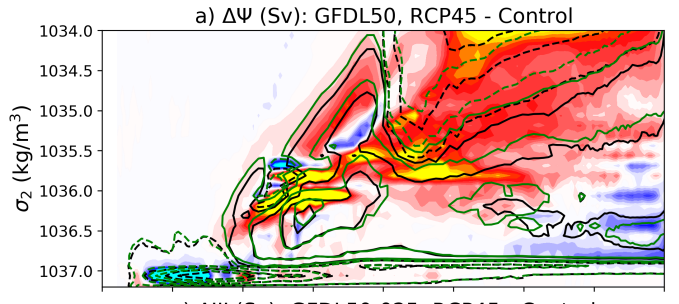

c) $\Delta \Psi$ (Sv): GFDL50-025, RCP45 - Control
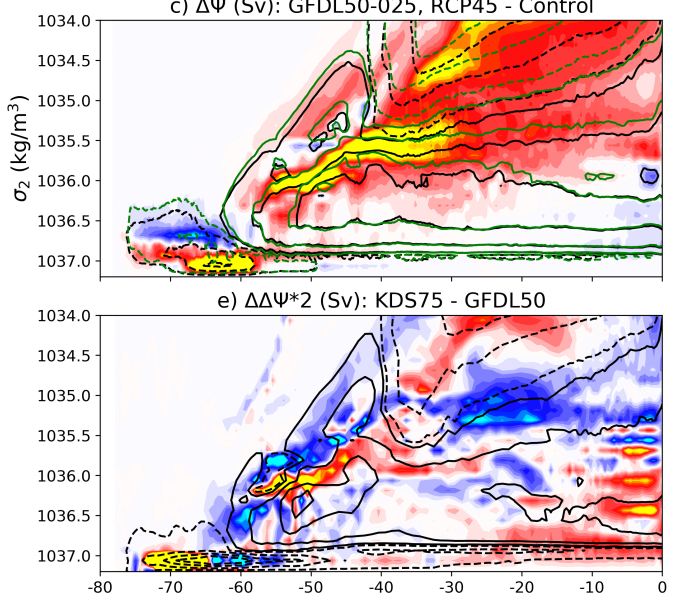

b) $\Delta \Psi$ (Sv): KDS75, RCP45 - Control

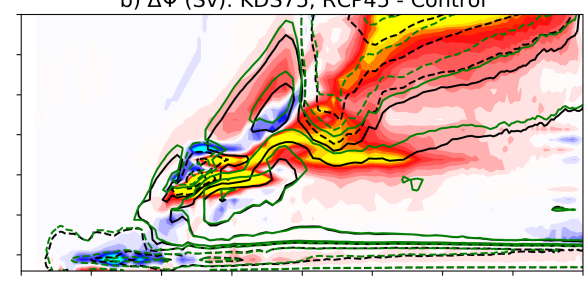

d) $\Delta \Psi$ (Sv): KDS75-025, RCP45 - Control

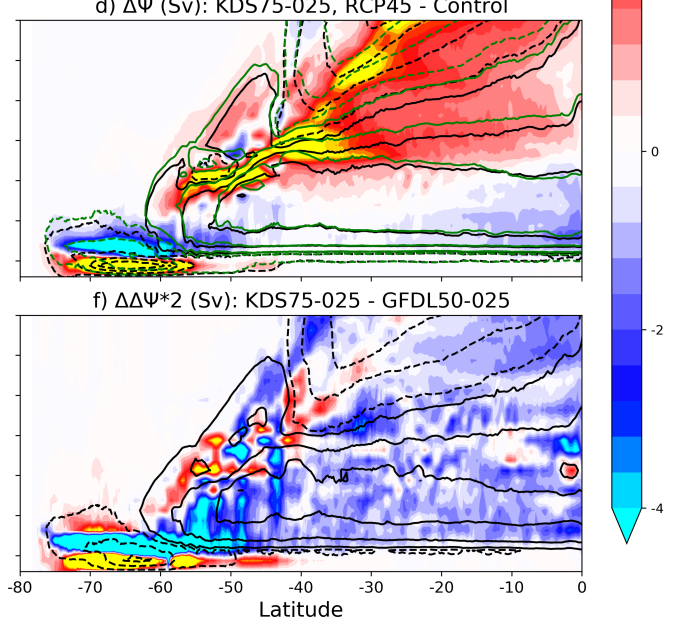

Figure 9: (a-d) Southern Hemisphere differences in overturning streamfunctions $(\Delta \Psi)$ in $\sigma_{2}$-latitude space for the simulations with the GFDL50 and KDS75 vertical grids. The streamfunctions for the control and RCP45 perturbation cases are contoured in black and green, respectively; the contour levels are at $\Psi= \pm 1,6,12,18$, with dashed contours as negative. (e,f) show the differences between the overturning anomalies $(\Delta \Delta \Psi)$ of the KDS75 and GFDL50 cases for the ACCESS-OM2 and ACCESS-OM2-025 simulations, respectively. Note these anomaly differences are scaled by a factor of 2 so as to be visible with the same colorscale. 
temperatures and volumes on $\sigma_{2}$, respectively. From this formulation, and with a sufficiently narrow $\sigma_{2}$ bin, it is clear that changes in $Q$ in a given $\sigma_{2}$ bin can arise from changes in $T_{\sigma_{2}}$ or $V_{\sigma_{2}}$. Considering the equation of state of seawater, substantial changes in $T_{\sigma_{2}}$ will require density-compensating changes in salinity in order for a water parcel to remain in a given $\sigma_{2}$ bin. Given that we impose no such perturbations to the hydrological forcing, we therefore expect the largest changes in $Q\left(\sigma_{2}\right)$ to arise from changes in $V_{\sigma_{2}}$. That is, heat increases or decreases in $\sigma_{2}$-space are characterised by the transformation of volume between $\sigma_{2}$ bins.

In order to compare between the model resolutions, the perturbationto-control change in total heat content for a given $\sigma_{2}$ bin is divided by the product of the thickness-weighted area average of that $\sigma_{2}$ bin and the cumulative model time under perturbation, returning a value for the rate of change of heat content for a given $\sigma_{2}$ bin, in dimensions of $\mathrm{W} / \mathrm{m}^{2}$. Figures 10a-d show this rate of heat content change in $\sigma_{2}$-longitude space for the simulations with GFDL50 and KDS75 vertical grids. Also indicated is $\sigma_{2}^{0, c}$, the northernmost $\sigma_{2}$ contour of the control simulation with zero wind stress curl at each longitude. The expected light-dense (north-south) dipole of heat increases and decreases about the $\sigma_{2}^{0}$ is obvious in all simulations. This representation of heat uptake, which is specifically the movement of volume between density classes, highlights the close coupling between the heat uptake and the location of the zero wind stress curl in $\sigma_{2}$-space. The dominant roles of the Pacific and Indian basins in ocean heat uptake are evident, particularly in regions with a zonally-coherent zero wind stress curl location in $\sigma_{2}$-longitude space. Furthermore, the lack of zonal coherence of the zero wind stress curl $\sigma_{2}^{0}$ in the Atlantic sector may account for the relatively weaker rates of heat uptake estimates there.

From Figures 10a-d it is apparent that the changes in heat content in $\sigma_{2}$-space for the simulations with GFDL50 are relatively stronger than those with KDS75. This is more evident in Figures 10e,f, which shows the difference between the rates of heat content change for KDS75 and GFDL50 simulations in $\sigma_{2}$-longitude space at $1^{\circ}$ and $0.25^{\circ}$ degree resolutions, respectively. Here the negative values for light $\sigma_{2}<1035.5 \mathrm{~kg} / \mathrm{m}^{3}$ indicate a relatively weaker heat increase (downwelling), and the positive values for denser $\sigma_{2}>1035.5 \mathrm{~kg} / \mathrm{m}^{3}$ indicate a relatively weaker heat decrease (upwelling), in the KDS75 simulations. The difference in the rate of heat content change on a given $\sigma_{2}$ is more pronounced in the ACCESS-OM2-025 simulations. This result that the GFDL50 simulations exhibit stronger rates of heat content 
change on $\sigma_{2}$ is consistent with the relative differences in surface momentum fluxes and wind stress curl on $\sigma_{2}$ between the coarse-surface-resolution GFDL50 and finer-surface-resolution KDS75 (e.g., Fig. 2-4).

The enhanced rates of heat content change exhibited by the simulations with GFDL50 are more apparent in their zonal averages either globally or by major ocean basin (Fig. 11a-d). The heat uptake rates for $\sigma_{2}<1035.5 \mathrm{~kg} / \mathrm{m}^{3}$ appear to be more sensitive to the vertical grid than the horizontal resolution; here the two simulations with the GFDL50 grid experience heat uptake rates at nearly twice that of the two simulations with KDS75. The isopycnal located at the zero wind stress curl represents a breakpoint in the heat uptake globally and in each basin; isopycnals immediately denser than the zero wind stress curl $\sigma_{2}$ exhibit the largest rates of heat decrease. This effect is least obvious in the Atlantic basin where the heat content change on isopycnals appears more complicated, presumably reflecting the zonal variability of the wind stress curl in both Eulerian and $\sigma_{2}$-space (Figs. 3 and 4 ). Additionally, the effect of horizontal resolution is most obvious in the strong heat decrease of the $\sigma_{2}$ immediately denser of the zero wind stress curl $\sigma_{2}$, a signal associated with the enhanced wind-driven upwelling apparent in ACCESSOM2-025.

We can take this analysis further by calculating the cumulative average rates of heat content change on isopycnals between $\sigma_{2}=1034.0 \mathrm{~kg} / \mathrm{m}^{3}$ (approximate density of the lightest surface waters at $35^{\circ} \mathrm{S}$ ) and $\sigma_{2}$, both globally and by major ocean basin (Fig. 11e-h). These curves indicate the average Southern Ocean heat uptake on $\sigma_{2}$ is positive and increasing up to the zero wind stress curl $\sigma_{2}^{0}$, beyond which it decreases rapidly, highlighting the importance of this isopycnal outcrop for locating heat uptake. Again, this diagnostic suggests the heat uptake is more sensitive to the vertical grid than the horizontal resolution, with the simulations that use the relatively coarse GFDL50 grid exhibiting heat increases at nearly twice the rate of the KDS75 simulations.

\section{Discussion}

The simulations and analysis shown in this manuscript demonstrate a number of important points which we list here and develop further in the following paragraphs:

1. that the surface speed, wind stress and wind stress curl are sensitive to the vertical resolution at the ocean surface; 
a) GFDL50, $\Delta Q /$ at on $\sigma_{2}$ by longitude $\left(W / \mathrm{m}^{2}\right)$

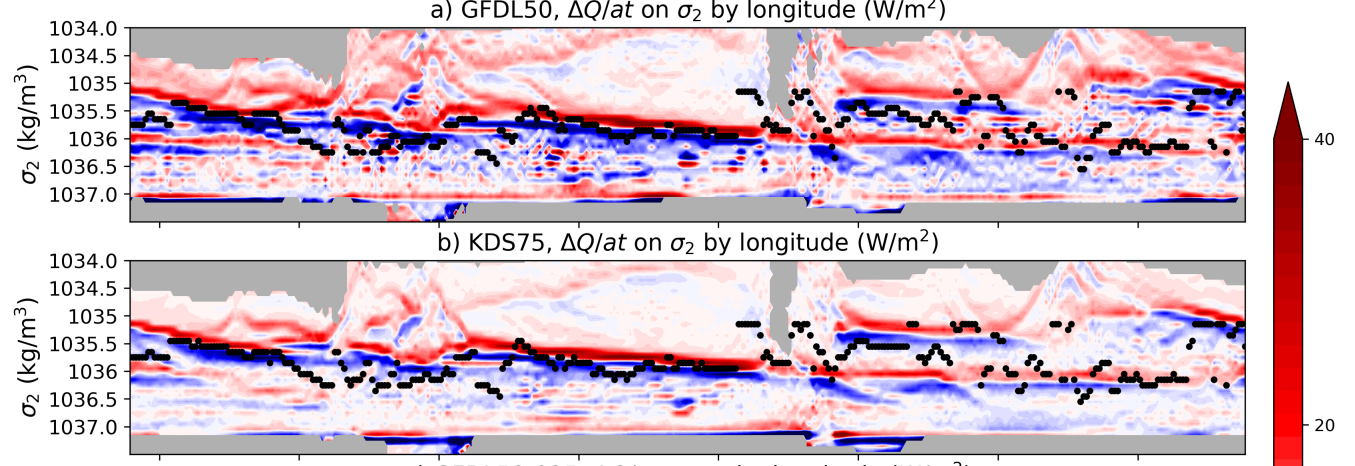

c) GFDL50-025, $\Delta Q /$ at on $\sigma_{2}$ by longitude $\left(\mathrm{W} / \mathrm{m}^{2}\right)$

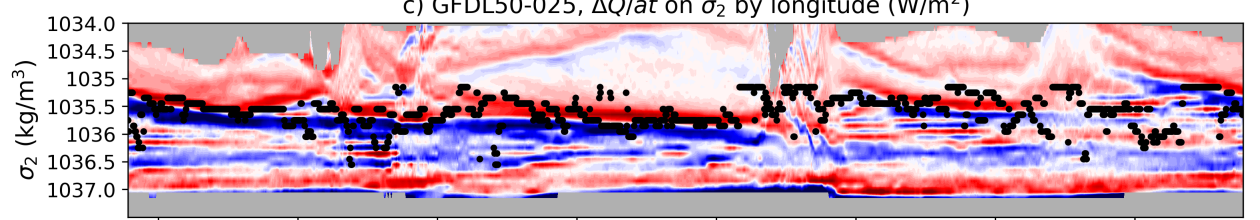

d) KDS75-025, $\Delta Q / a t$ on $\sigma_{2}$ by longitude $\left(\mathrm{W} / \mathrm{m}^{2}\right)$

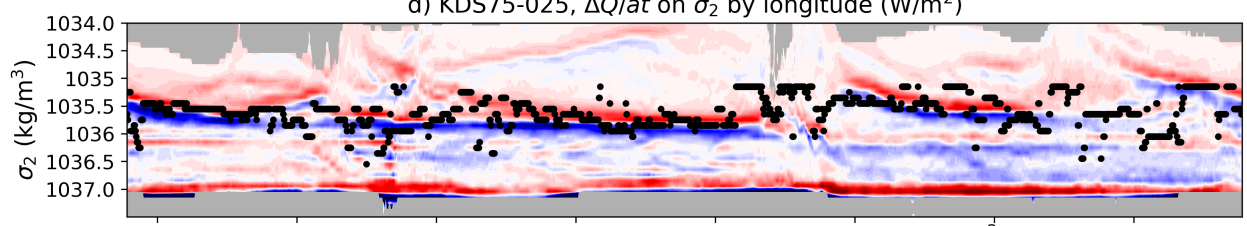

e) KDS75 - GFDL50, $2 * \Delta Q / a t$ on $\sigma_{2}$ by longitude $\left(\mathrm{W} / \mathrm{m}^{2}\right)$

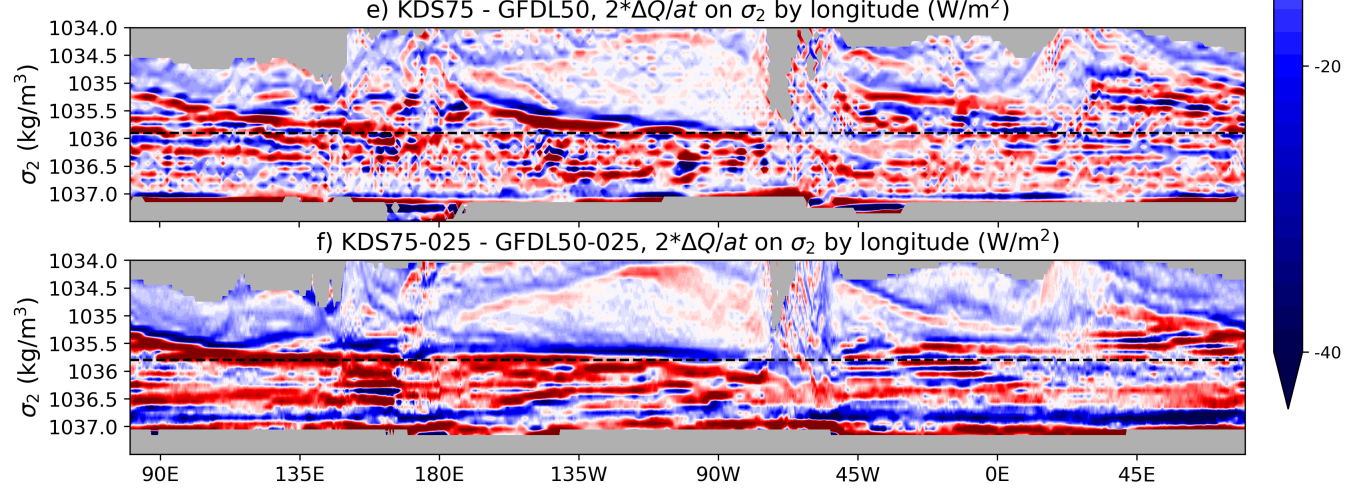

Figure 10: (a-d) The rates of heat content change $\left(\mathrm{W} / \mathrm{m}^{2}\right)$ in $\sigma_{2}$-space by longitude for the region bound by $2000 \mathrm{~m}$ and $35^{\circ} \mathrm{S}$ in the simulations with GFDL50 and KDS75 vertical grids at $1^{\circ}$ and $0.25^{\circ}$ horizontal resolutions. The northern-most location of zero wind stress curl for densities $>1035 \mathrm{~kg} / \mathrm{m}^{3}$ are indicated by the black dots. The KDS75-GFDL50 rate differences for (e) $1^{\circ}$ and (f) $0.25^{\circ}$ horizontal resolutions. Note the difference are scaled by a factor of 2 so as to be visible with the same colorscale. 

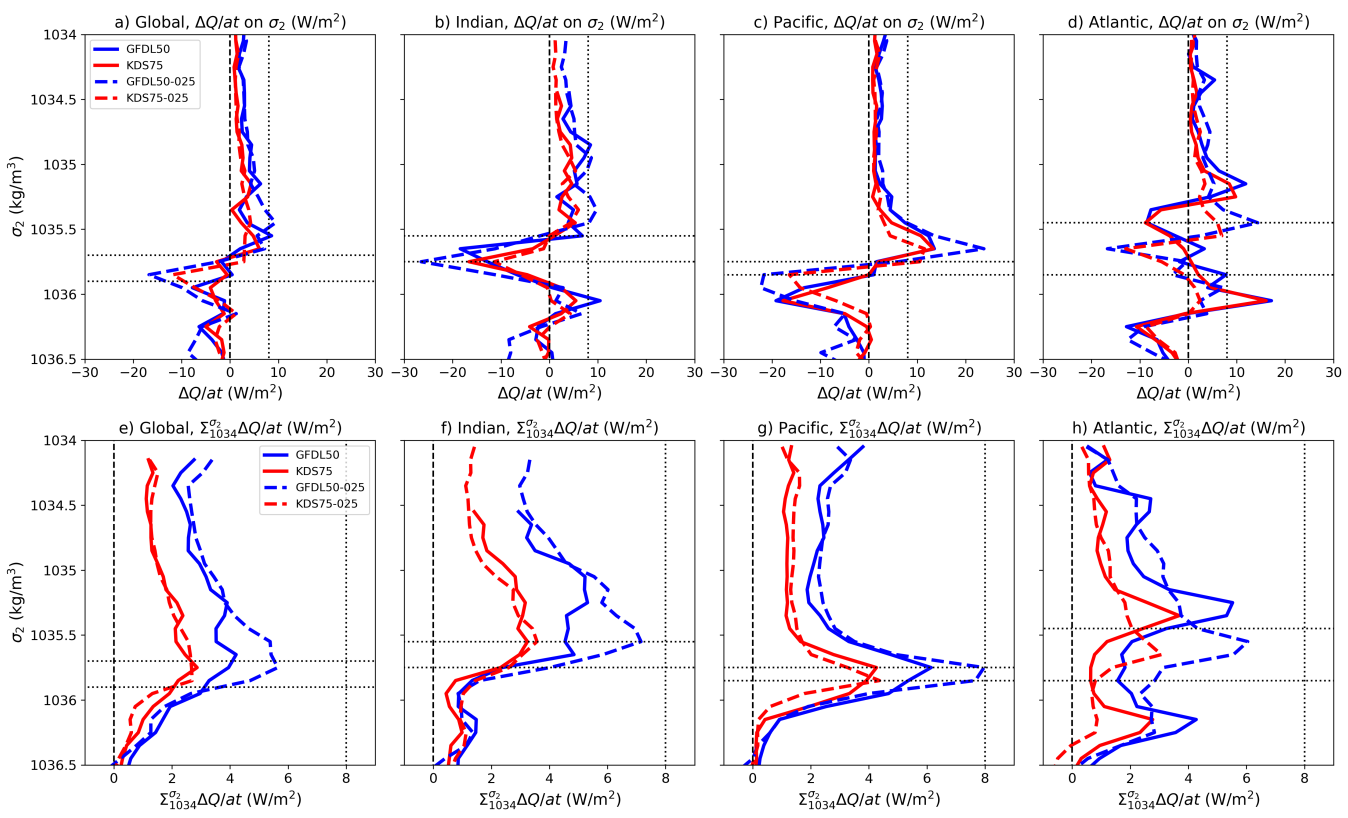

Figure 11: Zonal averages of the rates of heat content $\left(\mathrm{W} / \mathrm{m}^{2}\right)$ in $\sigma_{2}$-space for the simulations with GFDL50 and KDS75 vertical grids for the (a) Southern Ocean region of interest, (b) Indian, (c) Pacific and (d) Atlantic basins. For reference, the vertical dotted line at $8 \mathrm{~W} / \mathrm{m}^{2}$ indicates the imposed downward longwave radiation of the RCP45 perturbation, and the horizontal dotted lines indicate the range of the locations of zonally-averaged zero wind stress curl isopycnal, $\sigma_{2}^{0}$ for each of the regions. (e-h) The cumulative average rates of heat content change for $\sigma_{2}$ bins denser than $\sigma_{2}=1034.0 \mathrm{~kg} / \mathrm{m}^{3}$. 
2. that the surface momentum fluxes and associated upwelling can change from a purely thermal forcing perturbation;

3. that the zero wind stress curl isopycnal is critical to determine which regions experience an increase or decrease of heat when the system is perturbed;

4. that increased rates of heat uptake can occur with relatively coarse vertical resolution at the ocean surface; and

5. that the upwelling branch of the Southern Ocean circulation is enhanced when going from $1^{\circ}$ to $0.25^{\circ}$ resolution.

The sensitivity of the surface speed to the vertical resolution at the ocean surface (Fig. 2c) leads to a similar sensitivity in the wind stress field (e.g., Fig. 3 and Tab. 2). The differences in the spatial distribution of wind stress curl for simulations with coarse and fine surface vertical resolution suggest the simulations with coarse resolution will exhibit relatively enhanced wind-driven upwelling and downwelling in the Southern Ocean. The same analysis performed in $\sigma_{2}$-space (Fig. 4) suggests a more complicated resolution dependence as the isopycnals are free to move relative to the wind field. Nevertheless, for the ACCESS-OM2 simulations we expect enhanced wind-driven upwelling on isopycnals denser than the zero wind stress curl $\sigma_{2}$ in simulations with coarse resolution, which differs from the expectation for ACCESS-OM2-025, especially in the Indian and Atlantic basins. The simulations themselves show that the models with coarse vertical resolution at the ocean surface do indeed exhibit relatively stronger upwelling and downwelling about the zero wind stress curl isopycnal. An interesting point to consider is that as models continue to refine surface resolutions, and the ocean surface speed approaches the wind speed, does the Pacanowski (1987) method for calculating wind stress remain appropriate (Eqn. 1)? If not, should it begin to employ a bulk upper ocean speed that is resolution-independent, such as the ocean Ekman layer speed?

The purely thermal RCP45 perturbation imposed here acts to disrupt the three-way balance between the surface momentum fluxes, surface heat fluxes and ocean circulation. It initially warms the ocean surface, shifting the isopycnal outcrops poleward beneath the fixed winds, which subsequently operate on relatively less-dense waters. It follows that a purely hydrological perturbation could have a similar effect: if the imposed hydrological perturbation acted to freshen ocean surface and shift isopycnals to higher latitudes (as per the high latitude surface freshening trend of Durack \& Wijffels, 2010), 
we should expect similar thermal responses as those presented here. This expectation differs from the results of previous modelling efforts that impose freshwater perturbations (Armour et al., 2016; Pauling et al , 2016), calling for further investigations in this space.

Shifting the location of the zero wind stress curl to lighter waters has the effect of weakening the wind-driven downwelling of adjacent lighter waters, strengthening the wind-driven upwelling of adjacent denser waters, and reversing the wind-driven motions to now upwell waters between the old and new zero wind stress curl isopycnals. Our findings here indicate a leading order response to a purely thermal surface perturbation is the wind-driven upwelling of deep waters immediately denser than the new zero wind stress curl isopycnal. Considering that the deep ocean is a dominant carbon reservoir, this upwelling of deep waters could lead to a substantial outgassing of $\mathrm{CO}_{2}$ from the ocean to the atmosphere, potentially having dynamical consequences for Earth's climate.

The ocean-sea-ice simulations here employ the repeating wind field of JRA55-RYF8485. This strategy allows us to clearly separate cause and effect in these simulations, but in reality, the winds will also shift as Earth's climate changes. Observations and climate models agree that winds over the Southern Ocean are strengthening and shifting poleward. Alone, this poleward movement of the wind field would shift the location of the zero wind stress curl to a denser isopycnal. However, the atmosphere itself is warming and increasing the longwave radiation to the ocean, and changes in the hydrological cycle are freshening the ocean surface at high latitudes, all of which tend to shift the zero wind stress curl to a less-dense isopycnal. Presumably, additional degrees of freedom that enable the surface isopycnals and wind field to shift relative to one another will likely broaden to pattern of warming compared to that found here (e.g. Marshall et al., 2015). So the question now becomes one of competition between these opposing effects: in isopycnal space, are the winds shifting to denser isopycnals faster than the warming and freshening is reducing their densities?

The simulations here highlight the importance of the zero wind stress curl for locating the regions of heat increase and decrease in the Indian and Pacific Oceans. Considering the variability in ocean heat uptake and storage already present in CMIP5 models, this finding provides a framework for future investigations of heat uptake in climate and ocean models. Furthermore, the sensitivity of the wind-driven response to the vertical resolution at the ocean surface offers an additional means of delineating and understanding 
heat biases amongst models; from our findings here we expect the models with relatively coarse resolution at the ocean surface to have enhanced wind stress and therefore enhanced wind-driven processes. This sensitivity to the vertical resolution at the ocean surface is novel and of particular interest since previous resolution sensitivity studies typically focus on the effects of horizontal resolution (e.g., Spence et al., 2010; Newsom et al. , 2016). Given the expected refined horizontal resolution of the CMIP6 class of climate models, our results call for attention to the vertical resolution as well, especially at the ocean surface.

Our findings also provide guidance for investigating heat uptake in observations. Following on from Llovel \& Terray (2016), who identify shifts in the wind stress curl field associated with regions of heat uptake in observations, we link the changes of the wind stress curl to changes of the heat content in isopycnal space. In situ and gridded observational products of these fields are available, albeit from a range of observing platforms, making it possible to investigate this mechanism in observational data. This presents an avenue for future work on Southern Ocean heat uptake.

\section{Conclusion}

The simulations presented here were designed in part to examine the effect of model resolution on Southern Ocean heat uptake, predicated on hypothesis that spurious mixing may be altered at higher resolution. However, we found that the net rate of heat uptake depended only marginally on horizontal resolution. Instead, the biggest effect that resolution has involves the vertical resolution at the ocean surface, which influences the ocean surface speed and subsequently the wind stress exerted onto the ocean model. It follows that the Southern Ocean heat uptake itself is sensitive to the vertical resolution at the ocean surface; simulations with relatively coarse resolution at the surface (10m) exhibited Southern Ocean heat content changes at rates nearly double that of simulations with finer resolution at the surface $(1 \mathrm{~m})$. The biggest effect of increasing the horizontal resolution is in the wind-driven upwelling. A consistent finding in all simulations is that peak upwelling and downwelling straddle the isopycnal of zero wind stress curl. These findings are of particular interest for understanding Southern Ocean heat uptake in climate model intercomparison projects with varying ocean resolutions, and for identifying ocean warming signals in observations. 


\section{Acknowledgments}

Many thanks to M. England, R. Holmes and V. Tamsitt for very helpful discussions, and to the COSIMA consortium (www.cosima.org.au) for making available the ACCESS-OM2 suite of models. COSIMA is supported by an Australian Research Council Linkage Project (LP160100073). KDS was supported by the Australian Government Department of the Environment through the National Environmental Science Program (NESP). The numerical simulations and analysis were performed with the resources of the National Computational Infrastructure (Canberra, Australia), which is supported by the Australian Commonwealth Government.

\section{Bibliography}

Armour, K.C., J. Marshall, J.R. Scott, A. Donohoe \& E.R. Newsom (2016), Southern Ocean warming delayed by circumpolar upwelling and equatorward transport, Nature Geoscience, 9:549-554. DOI: 10.1038/NGEO2731

Bamber, J.L., M.R. van den Broeke, J. Ettema, J.T.M. Lenaerts \& E. Rignot (2012), Recent large increases in freshwater fluxes from Greenland into the North Atlantic, Geophysical Research Letters, 39, L19501. DOI: 10.1029/2012GL052552

Depoorter, M.A., J.L. Bamber, J.A. Griggs, J.T.M. Lenaerts, S.R.M. Ligtenberg, M.R. van den Broeke \& G. Moholdt (2013), Calving fluxes and basal melt rates of Antarctic ice shelves, Nature, 502, 89-92. DOI: 10.1038/nature 12567

Doddridge, E.W., D.P. Marshall \& A.McC. Hogg (2016), Eddy Cancellation of the Ekman Cell in Subtropical Gyres, Journal of Physical Oceanography, 46, 2995-3010. DOI: 10.1175/JPO-D-16-0097.1

Durack, P.J. \& S.E. Wijffels (2010), Fifty-Year Trends in Global Ocean Salinities and Their Relationship to Broad-Scale Warming, Journal of Climate, 23:4342-4362. DOI: 10.1175/2010JCLI3377.1

Frölicher, T.L., J.L. Sarmiento, D.J. Paynter, J.P. Dunne, J.P. Krasting \& M. Winton (2015), Dominance of the Southern Ocean in anthropogenic carbon and heat uptake in CMIP5 models, Journal of Climate, 28:862886. DOI: $10.1175 /$ JCLI-D-14-00117.1 
Fyfe, J.C. \& O.A. Saenko (2006), Simulated changes in Southern Hemisphere winds and currents, Geophysical Research Letters, 33, L01604. DOI: 10.1029/2005GL024464

Fyfe, J.C., O.A. Saenko, K. Zickfeld, M. Eby \& A.J. Weaver (2007), The Role of the Poleward-Intensifying Winds on Southern Ocean Warming, Journal of Climate, 20:5391-5400. DOI: 10.1175/2007JCLI1764.1

Gent, P.R. \& J.C. McWilliams (1990), Isopycnal mixing in ocean circulation models, Journal of Physical Oceanography, 20:150-155.

Griffies, S.M. (2012), Elements of the Modular Ocean Model (MOM) 5 (2012 release with updates), Technical Report 7, NOAA/Geophysical Fluid Dynamics Laboratory Ocean Group.

Griffies, S.M., M. Winton, W.G. Anderson, R. Benson, T.L. Delworth, C.O. Dufour, J.P. Dunne, P. Goddard, A.K. Morrison, A. Rosati, A.T. Wittenberg, J. Yin, and R. Zhang (2015), Impacts on ocean heat from transient mesoscale eddies in a hierarchy of climate models, Journal of Climate, 28, 952-977. DOI: 10.1175/JCLI-D-14-00353.1

Griffies, S.M., G. Danabasoglu, P.J. Durack, A.J. Adcroft, V. Balaji, C.W. Böning, E.P. Chassignet, E. Curchitser, J. Deshayes, H. Drange, B. FoxKemper, P.J. Gleckler, J.M. Gregory, H. Haak, R.W. Hallberg, P. Heimback, H.T. Hewitt, D.M. Holland, T. Ilyina, J.H. Jungclaus, Y. Komuro, J.P. Krasting, W.G. Large, S.J. Marsland, S. Masina, T.J. McDougall, A.J.G. Nurser, J.C. Orr, A. Pirani, F. Qiao, R.J. Stouffer, K.E. Taylor, A.M. Treguier, H. Tsujino, P. Uotila, M. Valdivieso, Q. Wang, M. Winton \& S.G. Yeager (2016), OMIP contribution to CMIP6: experimental and diagnostic protocol for the physical component of the Ocean Model Intercomparison Project, Geoscientific Model Development, 9, 3231-3296. DOI: 10.5194/gmd-9-3231-2016

Hallberg, R. (2013), Using a resolution function to regulate parameterizations of oceanic mesoscale eddy effects, Ocean Modelling 72, 92-103. DOI: 10.1016/J.OCEMOD.2013.08.007

Huber, M.B. \& L. Zanna (2017), Drivers of uncertainty in simulated ocean circulation and heat uptake, Geophysical Research Letters, 44. DOI: 10.1002/2017GL071587 
Hunke, E., W. Lipscomb, P. Jones, A. Turner, N. Jeffery, \& S. Elliott (2015), CICE, The Los Alamos Sea Ice Model, https://www.osti.gov//servlets/purl/1364126

Kiss, A.E., A.McC. Hogg, N. Hannah, F.B. Dias, G.B. Brassington, M.A. Chamberlain, C. Chapman, P. Dobrohotoff, C. Domingues, E.R. Duran, M.H. England, R. Fiedler, S.M. Griffies, A. Heerdegen, P. Heil, R.M. Holmes, A. Klocker, S.J. Marsland, A.K. Morrison, J. Munroe, P.R. Oke, M. Nikurashin, G.S. Pilo, O. Richet, A. Savita, P. Spence, K.D. Stewart, M.L. Ward, F. Wu \& X. Zhang (2019), ACCESS-OM2: A Global Ocean-Sea Ice Model at Three Resolutions, Geoscientific Model Development Discussions. DOI: 10.5194/gmd-2019-106

Kushner, P.J., I.M. Held \& T.L. Delworth (2001), Southern Hemisphere atmospheric circulation response to global warming, Journal of Climate, $14: 2238-2249$.

Large, W.G., J.C. McWilliams \& S.C. Doney (1994), Oceanic vertical mixing: A review and a model with a nonlocal boundary layer parameterization, Reviews of Geophysics, 32:363-403.

Levitus, S., J.I. Antonov, T.P. Boyer, O.K. Baranova, H.E. Garcia, R.A. Locarnini, A.V. Mishonov, J.R. Reagan, D. Seidov, E.S. Yarosh \& M.M. Zweng (2012), World ocean heat content and thermosteric sea level change (0-2000/,m), 1955-2010, Geophysical Research Letters, 39(10). DOI: $10.1029 / 2012$ GL051106

Lui, W., J. Lu, S.-P. Xie \& A. Fedorov (2018), Southern Ocean Heat Uptake, Redistribution, and Storage in a Warming Climate: The Role of Meridional Overturning Circulation, Journal of Climate, 31:4727-4743. DOI: 10.1175/JCLI-D-17-0761.1

Llovel, W. \& L. Terray (2016), Observed southern upper-ocean warming over 2005-2014 and associated mechanisms, Environmental Research Letters, 11:124023. DOI: 10.1088/1748-9326/11/12/124023

Locarnini, R.A., A.V. Mishonov, J.I. Antonov, T.P. Boyer, H.E. Garcia, O.K. Baranova, M.M. Zweng, C.R. Paver, J.R. Reagan, D.R. Johnson, M. Hamilton \& D. Seidov (2013), World Ocean Atlas 2013, Volume 1: 
Temperature. S. Levitus (Ed.), A. Mishonov (Technical Ed.); NOAA Atlas NESDIS, 73, 40pp.

Marshall, G.J. (2003), Trends in the Southern Annular Mode from observations and reanalysis, Journal of Climate, 16:4234-4143.

Marshall, J., J.R. Scott, K.C. Armour, J.-M. Campin, M. Kelley \& A. Romanou (2015), The ocean's role in the transient response of climate to abrupt greenhouse gas forcing, Climate Dynamics, 44:2287-2299. DOI: $10.1007 / \mathrm{s} 00382-014-2308-0$

Marsland, S.J., D. Bi, P. Uotila, R. Fiedler, S.M. Griffies, K. Lorbacher, S. O'Farrell, A. Sullivan, P. Uhe, X. Zhou \& A.C. Hirst (2013), Evaluation of ACCESS climate model ocean diagnostics in CMIP5 simulations, Australian Meteorological and Oceanographic Journal, 63, 101-119.

Morrison, A.K., O.A. Saenko, A.McC. Hogg \& P. Spence (2013), The role of vertical eddy flux in Southern Ocean heat uptake, Geophysical Research Letters, 40:5445-5450. DOI: 10.1002/2013GL057706

Morrison, A.K., S.M. Griffies, M. Winton, W.G. Anderson \& J.L. Sarmiento (2016), Mechanisms of Southern Ocean heat uptake and transport in a global eddying climate model, Journal of Climate, 29:2059-2075. DOI: 10.1175/JCLI-D-15-0579.1

Newsom, E.R., C.M. Bitz, F.O. Bryan, R. Abernathey \& P.R. Gent (2016), Southern Ocean Deep Circulation and Heat Uptake in a High-Resolution Climate Model, Journal of Climate, 29, 2597-2619. DOI: 10.1175/JCLID-15-0513.1

Oke, P.R. \& M.H. England (2004), Oceanic response to changes in the latitude of the Southern Hemisphere subpolar westerly winds, Journal of Climate, 17:1040-1054.

Pacanowski, R.C. (1987), Effect of Equatorial Currents on Surface Stress, Journal of Physical Oceanography, 17:833-838.

Pauling, A.G., C.M. Bitz, I.J. Smith \& P.J. Langhorne (2016), The Response of the Southern Ocean and Antarctic Sea Ice to Freshwater from Ice Shelves in an Earth System Model, Journal of Climate, 29:1655-1672. DOI: 10.1175/JCLI-D-15-0501.1 
Redi, M.H. (1982), Oceanic isopycnal mixing by coordinate rotation, Journal of Physical Oceanography, 12:1154-1158.

Roemmich, D., J. Church, J. Gilson, D. Monselesan, P. Sutton \& S. Wijffels (2015), Unabated planetary warming and its ocean structure since 2006, Nature Climate Change, 5(3):240-245, 50-65. DOI: 10.1038/nclimate2513

Sallée, J.-B., E. Shuckburgh, N. Bruneau, A.J.S. Meijers, T.J. Bracegirdle, Z. Wang \& T. Roy (2013), Assessment of Southern Ocean water mass circulation and characteristics in CMIP5 models: Historical bias and forcing response, Journal of Geophysical Research, 118(4):1830-1844. DOI: 10.1002/jgrc.20135

Sallée, J.-B. (2018), Southern Ocean warming, Oceanography, 32(2):52-62. DOI: $10.5670 /$ oceanog.2018.215

Snow, K., A.McC. Hogg, B.M. Sloyan, \& S.M. Downes (2016), Sensitivity of Antarctic Bottom Water to Changes in Surface Buoyancy Fluxes, Journal of Climate, 29, 313-330. DOI: 10.1175/JCLI-D-15-0467.1

Spence, P., J.C. Fyfe, A. Monrenegro \& A.J. Weaver (2010), Southern Ocean Response to Strengthening Winds in an Eddy-Permitting Global Climate Model, Journal of Climate, 23, 5332-5343. DOI: 10.1175/2010JCLI3098.1

Stewart, K.D., A.McC. Hogg, S.M. Griffies, A.P. Heerdegen, M.L. Ward, P. Spence \& M.H. England (2017), Vertical resolution of baroclinic modes in global ocean models, Ocean Modelling, 113, 50-65. DOI: 10.1016/j.ocemod.2017.03.012

Stewart, K.D., W. Kim, S. Urakawa, A.McC. Hogg, S. Yeager, H. Tsujino, H. Nakano, A.E. Kiss \& G. Danabasoglu (in prep.), JRA55-do Repeat Year Forcing, Ocean Modelling.

Swart, N.C. \& J.C. Fyfe (2012), Observed and simulated changes in the Southern Hemisphere surface westerly wind-stress, Geophysical Research Letters, 39, L16711. DOI: 10.1029/2012GL052810

Thompson, D.W.J., J.M. Wallace \& G.C. Hegerl (2000), Annular modes in the extratropical circulation. Part II: Trends, Journal of Climate, 13:10181036. 
Tsujino, H., S. Urakawa, H. Nakano, R.J. Small, W.M. Kim, S.G. Yeager, G. Danabasoglu, T. Suzuki, J.L. Bamber, M. Bentsen, C.W. Böning, A. Bozec, E.P. Chassignet, E. Curchitser, F.B. Dias, P.J. Durack, S.M. Griffies, Y. Harada, M. Ilicak, S.A. Josey, C. Kobayashi, S. Kobayashi, Y. Komuro, W.G. Large, J. Le Sommer, S.J. Marsland, S. Masina, M. Scheinert, H. Tomita, M. Valdivieso \& D. Yamazaki (2018), JRA-55 based surface dataset for driving ocean-sea-ice models (JRA55-do), Ocean Modelling, 130, 79-139. DOI: 10.1016/j.ocemod.2018.07.002

Wolfe, C.L. \& P. Cessi (2011), The Adiabatic Pole-to-Pole Overturning Circulation, Journal of Physical Oceanography, 41:1795-1810. DOI: 10.1175/2011JPO4570.1

Xie, P. \& G.K. Vallis (2011), The passive and active nature of ocean heat uptake in idealized climate change experiments, Climate Dynamics, 38:667684. DOI: $10.1007 / \mathrm{s} 00382-011-1063-8$

Zweng, M.M., J.R. Reagan, J.I. Antonov, R.A. Locarnini, A.V. Mishonov, T.P. Boyer, H.E. Garcia, O.K. Baranova, D.R. Johnson, D. Seidov \& M.M. Biddle (2013), World Ocean Atlas 2013, Volume 2: Salinity. S. Levitus (Ed.), A. Mishonov (Technical Ed.); NOAA Atlas NESDIS, 74, 39pp. 